\title{
Nitrile Oxide/Alkyne Cycloadditions - A Credible Platform for Synthesis of Bioinspired Molecules by Metal-Free Molecular Clicking
}

\author{
Frances Heaney*[a]
}

\begin{abstract}
Keywords: Bioorganic chemistry / Click chemistry / 1,3-Dipolar cycloaddition / Strain-promoted cycloaddition / Nucleic acids / Polymers / Alkynes

The need for precise and flexible synthetic methodology to underpin modern research in chemical biology and materials science has fuelled a resurgence of interest in Huisgen 1,3dipolar cycloaddition chemistry. Of late, the in vogue chemistry for the assembly of complex biological molecules and specialist materials has been the copper-catalysed azide alkyne cycloaddition (CuAAC) reaction. However, in certain circumstances aversion to the copper catalyst flaws this approach and alternatives have been sought. Click chemistry has de-

veloped beyond the original triazole-forming trick and azides are no longer the only dipoles pursued as click cycloaddition partners. This article reviews some of the complications of the $\mathrm{CuAAC}$ reaction and evaluates the potential of nitrile oxide/alkyne cycloaddition (NOAC) as a covalent conjugation tool. With a focus on applications in nucleic acid chemistry and materials science it presents the case for a prominent position for nitrile oxides in the catalyst-free bioconjugation toolbox.
\end{abstract}

\section{Introduction}

Transformations classified as "click reactions" ${ }^{[1]}$ encompass those allowing rapid and reliable creation of diverse chemical entities simply by joining molecular pieces as easily as one might click a buckle. To be in this illustrious club, reactions must be wide in scope, easily performed under mild conditions, insensitive to oxygen and water and proceed in a benign solvent or under solvent-free conditions. They must use easily accessible reagents and display orthogonality with other common reactants. The reactions ought to be spontaneous, with a thermodynamic driving force greater than $20 \mathrm{kcalmol}^{-1}$ and result in almost complete conversion of reactants to a single product without the need for extensive purification.

During the last decade these privileged reactions have become valued in industry and academia; applications transverse biomedical research, drug design, biotechnology and

[a] Department of Chemistry, National University of Ireland, Maynooth, Co. Kildare, Republic of Ireland Fax: +353-1-7083815

E-mail: mary.f.heaney@nuim.ie materials science. Publications have increased exponentially, totalling about 5000 to date, including almost 200 review articles and a specialist monograph. ${ }^{[2]}$ Entire issues of QSAR \& Combinatorial Chemistry [2007, 26 (11-12)], Macromolecular Rapid Communications [2008, 29 (12-13)] and Chemical Society Reviews [2010, 39 (4)] have been dedicated to click chemistry; most recently Accounts of Chemical Research has published a themed issue on bioorthogonal chemistry [2011, 44 (9)].

\section{The Click Toolbox}

The click toolbox is ever expanding and practitioners can choose their tool to reflect a preference for selectivity or sensitivity. Favoured reactions include nucleophilic opening of spring-loaded electrophiles ${ }^{[3 \mathrm{a}]}$ and nucleophilic addition to carbonyl substrates yielding oximes and hydrazones, ${ }^{[3 \mathrm{~b}]} \mathrm{a}$ variety of thiol chemistries ${ }^{[4]}$ and cycloaddition reactions including the Diels-Alder reaction. ${ }^{[5]}$ However, the widespread adoption of the copper(I)-catalysed azide/alkyne cycloaddition - the so-called CuAAC reaction - has made it almost synonymous with the term "click chemistry".



Frances Heaney studied Chemistry and Biochemistry at Queen's University, Belfast. After graduating with an Hons BSc degree she remained in Belfast. In 1990 she attained a PhD in chemistry under the supervision of Professor Ron Grigg. She spent two years as a post-doctoral researcher in Trinity College, Dublin, before being appointed to the staff at the National University of Ireland Galway. She subsequently moved to the National University of Ireland Maynooth, where she is now senior lecturer. 


\section{The Gold Standard CuAAC Reaction}

In its modern genesis, ${ }^{[1,6]}$ the triazole-forming CuAAC reaction, discovered at the end of the 19th century ${ }^{[7]}$ and studied extensively by Huisgen ${ }^{[8]}$ in the 1960 s, has been utterly transformed. It is now known that the poor kinetics and selectivity of the classic thermal reaction can be overcome by the addition of a catalytic amount of copper. The CuAAC reaction is the most championed click reaction, with applications in supramolecular ${ }^{[9]}$ materials $^{[10]}$ and polymer chemistry. ${ }^{[11]}$ It has also been central to the synthesis of drug candidates ${ }^{[12]}$ and nucleoside analogues; ${ }^{[13]}$ other bioinspired applications include protein engineering, ${ }^{[2]}$ biological imaging ${ }^{[14]}$ and biomimetic modelling. ${ }^{[15]}$

\subsection{Drawbacks to Copper-Catalysed Azide/Alkyne Cycloadditions}

Despite its status as the quintessential click reaction, the CuAAC is not ubiquitously attractive. ${ }^{[16]}$ It requires optimisation of a number of reagents and the need for the $\mathrm{Cu}(1)$ catalyst can be limiting. Toxicity is problematic for reactivity in living systems, in tissue engineering applications and in development of therapeutics. ${ }^{[17]}$ The cytotoxic copper ions ${ }^{[18]}$ can cause oxidative damage including DNA degradation and polysaccharide or protein denaturation. ${ }^{[19]}$ Catalytic copper ions are incompatible with some synthetic targets, such as those incorporating chelating or Fischer carbene moieties. ${ }^{[20]}$ In other cases, product entrapment of the catalyst ions has necessitated the use of stoichiometric amounts of copper and has resulted in polymeric materials with inferior properties to those formed by classical thermal polymerisation methods. ${ }^{[21]}$ Trace copper is especially problematic in the pharmaceutical sector, where levels must remain below $15 \mathrm{ppm} .{ }^{[22]}$ Catalyst impurities impact negatively on enzyme-linked immunosorbent assays (ELIZA), on the biochemical properties of labelled phages and the luminescence characteristics of quantum-dot-functionalised biomolecules. ${ }^{[23]}$

\subsection{General Solutions to the Problems of Residual Copper}

A palette of tools designed to circumvent problems associated with the presence of residual copper is emerging. In limited circumstances the reactions might proceed satisfactorily in the absence of copper (e.g. with "activated" substrates $^{[24]}$ ) or with the application of specialised experimental techniques (e.g. microcontact printing ${ }^{[25]}$ ). However, more general solutions are desirable. One approach involves extensive washing to eliminate residual copper ions; ${ }^{[26]}$ another relies on catalyst remediation (e.g., sequestration by oxide-capped metallic iron nanoparticles, FexOy@Fe). ${ }^{[22]}$ Alternatively, judicious choice of copper source can facilitate removal by simple filtration [e.g., $\mathrm{Cu}^{\mathrm{I}}$-zeolites, benchstable copper-in-charcoal or copper nitride $\left(\mathrm{Cu}_{3} \mathrm{~N}\right)$ nanoparticles supported on a superparamagnetic silica microsphere]. ${ }^{[27]}$ Still other approaches rely on catalyst formula- tions free of cytotoxicity; practical solutions include conducting the reaction under air-free conditions or with $\mathrm{Cu}^{\mathrm{I}}$ stabilizing ligands (e.g., TBTA, BTTES or BTTAA). ${ }^{[28]}$ The last two, tris(triazolylmethyl)amines, are especially attractive; they confer improved kinetics and bio-benign status on the CuAAC reaction. Finally, "ligandless" click ligation or labelling of unprotected RNA substrates has been facilitated by judicious choice of reaction solvent or alkyne partner. ${ }^{[29]}$

\subsection{Ruthenium as a Replacement for the Copper Catalyst}

Ruthenium-catalysed azide/alkyne cycloadditions (RuAACs), with regiochemical complementarity to the $\mathrm{Cu}-$ promoted version have been developed ${ }^{[27 b, 30]}$ (Scheme 1). Several $\mathrm{Ru}^{\mathrm{II}}$ complexes are catalytically active, and whilst $\mathrm{Cp} * \mathrm{RuCl}\left(\mathrm{PPh}_{3}\right)_{2}$ is the most widely adopted the nature of the reacting azide informs the choice of catalyst. ${ }^{[31]}$ In some instances sluggish reactivity can be overcome by microwave irradiation. ${ }^{[31 b]}$ The reaction is compatible with both terminal and internal alkynes, although with the latter there can be some compromise in regioselectivity. ${ }^{[30 \mathrm{~b}, 30 \mathrm{c}]}$ Applications have been reported in materials ${ }^{[32]}$ and medicinal chemistry, ${ }^{[33]}$ as well as in the preparation of nucleoside and sugar derivatives, peptide surrogates and aminoacyl-tRNA analogues. ${ }^{[34]}$

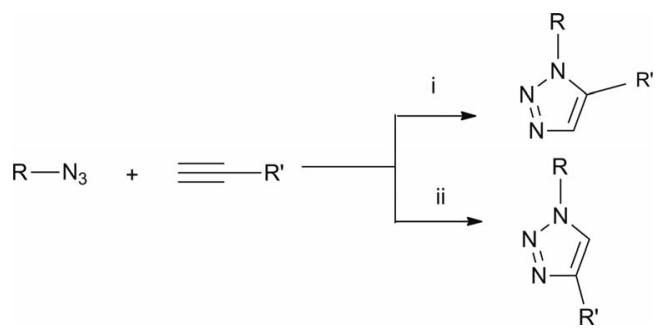

Scheme 1. Catalyst-controlled regioselective cycloadditions of azides and terminal alkynes: i) $\mathrm{Cp} * \mathrm{RuCl}\left(\mathrm{PPh}_{3}\right)_{2}, \mathrm{PhH}$, reflux; [30b] ii) sodium ascorbate, $\mathrm{CuSO}_{4}, t \mathrm{BuOH}, \mathrm{H}_{2} \mathrm{O}$, room temp.

\subsection{Alkynes with Enhanced Reactivities - SPAAC}

The poor kinetics of the CuAAC reaction at the concentrations desirable for bioconjugation have been addressed by the development of strain-promoted azide/alkyne cycloaddition (SPAAC) chemistry. The significant reduction in the activation barrier makes the requirement for a catalyst redundant and, depending on the application, SPAAC reactions can compete with the best $\mathrm{CuAAC}$ protocols. ${ }^{[23 \mathrm{~b}]} \mathrm{Nu}$ merous cyclooctyne probes have been developed (Figure 1). Incremental improvements on first-generation cyclooctynes $^{[23 b, 35]}$ have yielded azacyclooctynes with enhanced aqueous solubilities, as well as $\alpha$-fluorinated and $\alpha, \alpha$-difluorinated versions with improved kinetics. ${ }^{[20 a, 36]}$ Diarylcyclooctynes, generated by classical or photochemical approaches, ${ }^{[37]}$ their aza analogues [azadibenzocyclooctynes (ADIBOs)], ${ }^{[38]}$ including some carrying fluorescent or radio-reporting tags, ${ }^{[39]}$ and the highly sensitive biarylazacy- 
clooctynones $(\text { BARACs })^{[40]}$ all show enhanced reactivities allowing reactions to occur within minutes rather than hours. The superior kinetics of these reagents are important in living systems in which reactivity must be faster than metabolic probe elimination. In spite of its obvious attractions the SPAAC reaction carries a penalty of poor regioselectivity ${ }^{[38 b]}$ and recent in vivo studies revealed that difluorooctyne-based (DIFO-based) probes bind nonspecifically to mouse serum albumin, presumably through formation of covalent bonds between cysteine residues and the cyclooctyne. $^{[36 \mathrm{~d}]}$

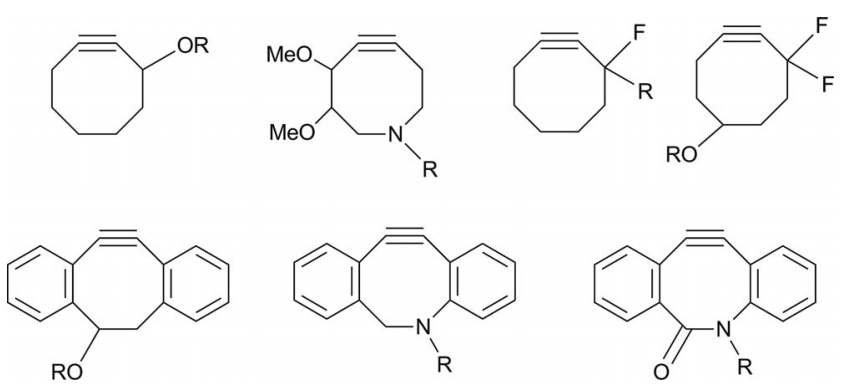

Figure 1. Representative cyclooctyne partners in SPAAC reactions.

\section{Nitrile Oxides (and Nitrones) - Dipoles of Enhanced Reactivity}

The utility of dipoles other than azides has progressed click chemistry beyond the triazole conjugating tool. We and others have focused on nitrile oxide and nitrone cycloadditions; the ensuing cycloadducts - isoxazoles and their partially saturated analogues - are, like the triazole nucleus, an important class of heterocycle. The potential issue of dipole instability, manifest in nitrile oxide dimerisation or in nucleophile trapping, ${ }^{[41]}$ is minimised by in situ generation and by judicious choice of reacting partner. The isoxazole-generating nitrile oxide-alkyne cycloaddition (NOAC) has many attractions:

Firstly, there is the ease and range of procedures available for dipole formation from oxime substrates by direct or indirect oxidative methods, or from nitro precursors in the

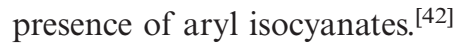

Secondly, there are the attractive kinetics. The NOAC is estimated theoretically, and observed experimentally ${ }^{[43]}$ to have more attractive kinetics than similar azide cycloadditions.

Thirdly, there is regioselectivity. Reactions of nitrile oxides with monosubstituted alkynes lead regioselectively to 3,5-disubstituted adducts. ${ }^{[44]}$

Fourthly, there is synthetic utility. Despite its status as a rather stable aromatic moiety the isoxazole nucleus masks a variety of functionalities potentially valuable in subsequent manipulations. ${ }^{[45]}$ In addition to agrochemical applications, isoxazole derivatives are valued pharmacophores. Present in many natural and synthetic bioactive compounds, including ibotenic acid and the COX-2 inhibitor valdecoxib, the isoxazole system is hydrolytically stable. It shares the isosteric character of amide and ester bonds and has potential for $\pi$-stacking and $\mathrm{H}$-bonding, and so it has many possible modes of action with biological molecules. ${ }^{[46]}$

Finally, in contrast to azides, there are only limited issues relating to health and safety in the handling of the dipole. $^{[47]}$

\subsection{Catalyst-Promoted Cycloadditions between Alkynes and Nitrile Oxides/Nitrones}

Most nitrile oxide cycloadditions are catalyst-free, but regiocomplementary control has been demonstrated in the presence of a copper, ${ }^{[48]}$ an $N$-heterocyclic carbene $(\mathrm{NCH})^{[49]}$ or a ruthenium catalyst. ${ }^{[50]}$ Both the copper- and the carbene-mediated reactions promote formation of 3,5disubstituted isoxazoles, whereas ruthenium catalysis favours 3,4-disubstituted ones (Scheme 2). Active copper(I) catalysts have been obtained from copper(II) sulfate either by ascorbate reduction or by comproportionation with copper metal. Nitrile oxide generation involved either base treatment of the desired hydroxamoyl chloride or reaction between the parent oximes and either chloramine-T or NCS and base. The reactions, predicted by computational models to be much faster than with similar azides, do indeed proceed with remarkable acceleration. The catalysed reactions have been shown to be tolerant of a number of functional groups, although to date the conjugated oestradiol in Figure 2 remains the only bioinspired example.

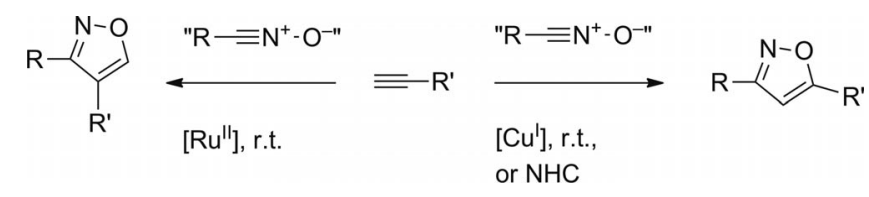

Scheme 2. Catalyst-controlled regioselective cycloaddition reactions between nitrile oxides and terminal alkynes. Nitrile oxides generated in situ either from aldoximes by treatment with chloramine- ${ }^{[48]}$ or through action of base on imidoyl chlorides $[\mathrm{RC}(\mathrm{Cl})=\mathrm{NOH}] .^{[49,50]}$

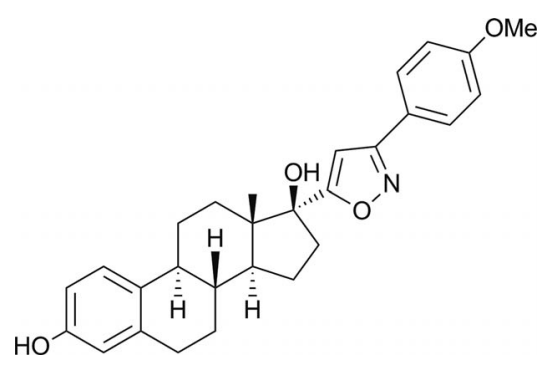

Figure 2. Oestradiol conjugate prepared by $\mathrm{Cu}(1)$-promoted nitrile oxide/alkyne cycloaddition. ${ }^{[48 a]}$

Reactions between nitrones and terminal alkynes have limited synthetic appeal, but depending on their substitution patterns the resulting $\Delta^{4}$-isoxazolines are susceptible to a variety of decomposition behaviour patterns. ${ }^{[51]}$ Neither are the $\mathrm{Cu}^{\mathrm{I}}$-catalysed reactions useful for generating isoxazoline-linked conjugates; under click conditions the ini- 
tially formed cycloadducts undergo immediate collapse to monocyclic $\beta$-lactams through Kinugasa-type reactions; see Eq. (1). ${ }^{[52]}$
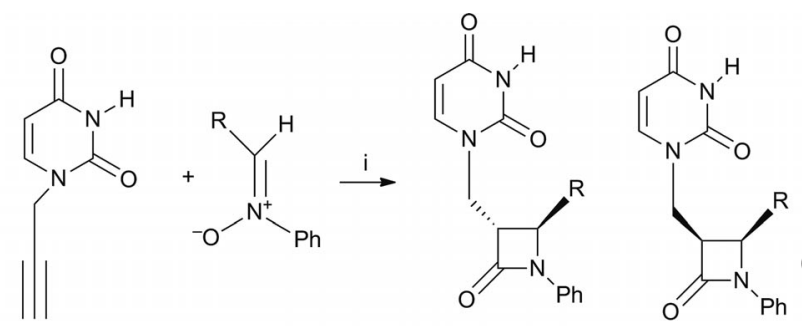

Preparation of $\beta$-lactam nucleobases from $\mathrm{Cu}$-promoted nitrone-alkyne coupling. Conditions i: $\mathrm{CuSO}_{4}$, sodium ascorbate, $\mathrm{NEt}_{3}, \mathrm{DMF} / \mathrm{H}_{2} \mathrm{O}^{[52]}$

\section{Bioinspired Syntheses Based on Catalyst-Free Cycloadditions between Nitrile Oxides/Nitrones and Terminal Alkynes}

\subsection{Nucleoside Analogues}

Nitrile oxide/alkyne cycloaddition (NOAC) chemistry is central to the synthesis of a number of bioinspired compounds, including steroid and sugar conjugates, with in situ generation of active dipoles from oximes, hydroxamoyl chlorides or nitro compounds. ${ }^{[53]}$ This field is dominated, however, by the antiviral and anticancer potential of isoxazole nucleoside analogues. Nitrile oxide approaches to nucleoside derivatives with the nucleoside tagged either with the dipolarophile or with the dipole precursor have been demonstrated; both nucleobase- and ribose-modified oximes have served as nitrile oxide precursors, ${ }^{[44,54]}$ whereas alkyne functionalities have more commonly been placed on the base than on the sugar. ${ }^{[13,55]}$ In the reports to date, Na$\mathrm{OCl}$ alone, $\mathrm{NaOCl}$ with $\mathrm{NEt}_{3}$, or NCS/NBS with $\mathrm{NEt}_{3}$ have most frequently been selected as dipole generating agents, although commercial bleach ${ }^{[55 b]}$ and hypervalent iodine reagents such as $\mathrm{PhI}\left(\mathrm{OCOCF}_{3}\right)_{2}(\mathrm{PIFA})^{[56]}$ present other options. PIFA, suited to generation of both nucleoside and peptide conjugates, has reasonable functional group tolerance and examples of nucleoside analogues generated by this methodology are illustrated in Figure $3 \cdot{ }^{[56]}$ In one recent example a solid-phase approach was demonstrated, ${ }^{[13]}$ though more generally the cycloadditions are reported in solution with THF or $\mathrm{CH}_{2} \mathrm{Cl}_{2}$ as reaction solvent.

Conjugation in aqueous media is highly desirable for bioapplications; accordingly, the preparation of modified nucleosides by NOAC induced by chloramine- $\mathrm{T}$ is a significant goal. ${ }^{[57]}$ The use of chloramine-T in the generation of isoxazole-linked peptidomimetics, ${ }^{[48 \mathrm{~b}]}$ in antibody-catalysed cycloaddition reactions and in the preparation of ${ }^{125} \mathrm{I}-\mathrm{lab}-$ elled oligonucleotides ${ }^{[58]}$ suggests, with judicious choice of reactant concentrations, harmony with biological systems.

Chloramine-T mediates nitrile oxide formation from aldoxime precursors; it is also capable of transforming
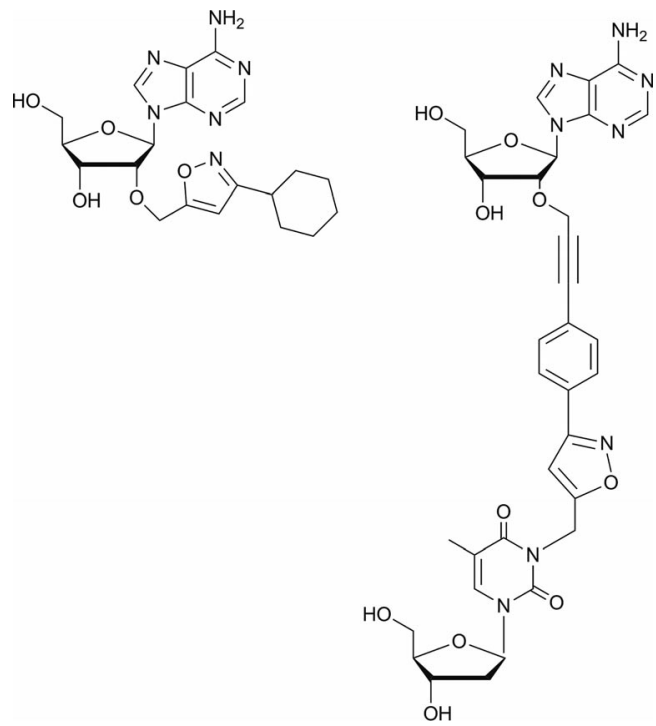

Figure 3. Nucleoside conjugates prepared by NOAC; nitrile oxides generated from oximes by $\mathrm{PhI}\left[\mathrm{OC}(\mathrm{O}) \mathrm{CF}_{3}\right]_{2}$-induced oxidation. ${ }^{[56]}$

hydrazones into nitrile imines. ${ }^{[59]}$ The choice of this reagent for nitrile oxide generation facilitates a move away from the biphasic (water/ $\mathrm{CH}_{2} \mathrm{Cl}_{2}$ ) systems desirable for the NCS/ NBS $\mathrm{NEt}_{3}$ protocols and found to be valuable for rate enhancements of NaOCl-promoted intramolecular cycloadditions. ${ }^{[60]}$ Chloramine- $\mathrm{T}$ is a versatile reagent that can be used with both acid- and base-sensitive substrates. Issues relating to base-sensitive substrates have been circumvented by co-employment of silica gel, ${ }^{[53 a]}$ whereas the presence of a mild base (e.g., $\mathrm{NaHCO}_{3}$ ) is sufficient to protect acidsensitive functionalities. One plausible mechanism for the transformation of aldoximes into nitrile oxides through chloramine-T induction is shown in Scheme 3. ${ }^{[59]}$ For application of the chloramine- $T$ protocol a number of caveats apply; one should heed Padmavathi's observations that side reactions of the initially generated nitrile oxide with excess chloramine-T (4 equiv.) can give undesired products and detract from the yield of the desired dipole, ${ }^{[59]}$ as well as Rai's observations that some reaction partners (e.g., vinyl sulfones) might not be inert to the oxidising power of chloramine-T. A pragmatic solution to the latter problem involves exposure of the oxime to the chloramine-T prior to addition of the dipolarophile. ${ }^{[61]}$

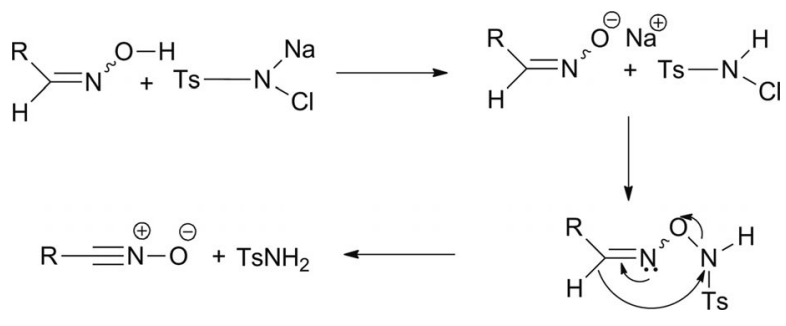

Scheme 3. Mechanism proposed by Padmavathi and co-workers for the formation of nitrile oxides from oximes through chloramine-T induction. ${ }^{[59]}$ 
Nucleoside analogues can be formed by nitrile oxide click chemistry induced by chloramine-T either conventionally in solution or also under solid-phase conditions. ${ }^{[62]}$ Many antiviral nucleoside analogues require 5'-hydroxy groups for kinase phosphorylation, but some $5^{\prime}$-tritylated derivatives demonstrate inhibition of thymidine phosphorylase and angiogenesis, ${ }^{[63]}$ so access both to $5^{\prime}$-protected and to $5^{\prime}$-unprotected thymidine derivatives is important.

Thymidine substrates bearing free hydroxy groups at their 5'-positions, as well as those protected as trityl or dimethoxytrityl ethers, are compatible with the NOAC protocol with chloramine-T induction. Propargyl moieties, easily introduced at the $3^{\prime}$-position of the deoxyribose moiety, can function as the alkyne handles and the active dipoles can be generated from the parent oximes by treatment with chloramine- $\mathrm{T}$ in aqueous ethanolic $\mathrm{NaHCO}_{3}$. The one-pot, catalyst-free protocol avoids issues with reactive oxygen species and there is no requirement to exclude air from the reaction. Cycloadditions to the protected and unprotected nucleosides $\mathbf{1}$ and $\mathbf{2}$ are complete after stirring for $1 \mathrm{~h}$ at room temperature (Scheme 4). The reactions allow selective formation of 3,5-disubstituted isoxazoles $\mathbf{3 / 4}$, as is evident in the ${ }^{1} \mathrm{H}$ NMR spectra of the products; the 4- $H$ protons of the isoxazole rings are each characterised by a singlet resonance at about $6.5 \mathrm{ppm}$. The isoxazole ring protons of the alternative 3,4-disubstituted regioisomers ought to resonate approximately $1 \mathrm{ppm}$ further downfield. ${ }^{[50]}$

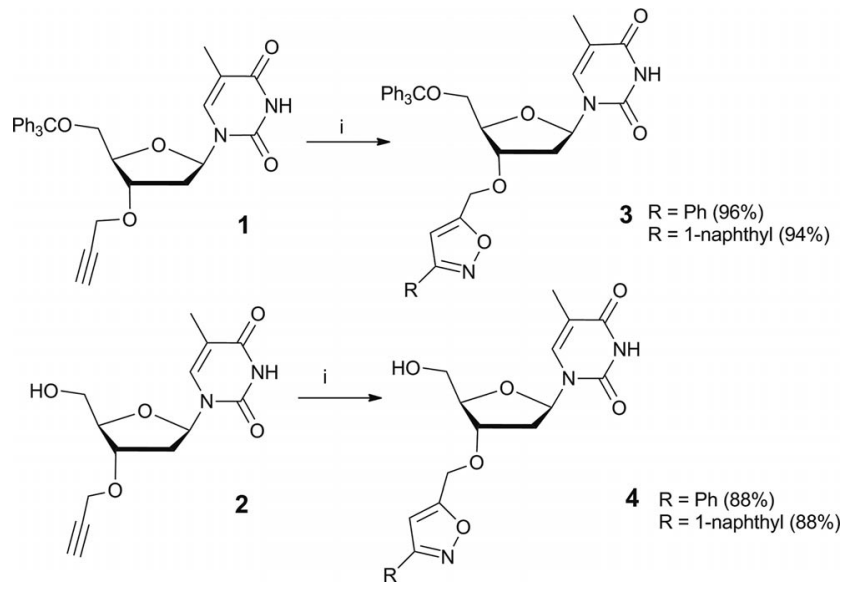

Scheme 4. Thymidine conjugates prepared through cycloadditions between terminal alkynes and nitrile oxides generated by the chloramine-T protocol: i) $\mathrm{RCHNOH}$, chloramine-T, $\mathrm{NaHCO}_{3}, \mathrm{EtOH} /$ $\mathrm{H}_{2} \mathrm{O}, 1$ h, r.t. ${ }^{[62 \mathrm{~b}]}$

Nucleoside derivatives conjugated with two identical groups can be accessed by "click-click" NOAC. $C^{3 \prime}, O, N^{3}-$ Bispropargyl thymidines 5 or $\mathbf{6}$ (Scheme 5), for example, with the $5^{\prime}$-hydroxy group either tritylated or free, can function as bis-dipolarophiles. These substrates, when exposed to suitable oximes and chloramine-T, can undergo two independent nitrile oxide/alkyne click cycloaddition reactions. As was evident from their ${ }^{1} \mathrm{H}$ NMR spectra, the double cycloaddition products $\mathbf{7 / 8}$ form without any compromise in regioselectivity. Concomitant with cycloaddition is the disappearance of the alkyne proton resonance and down- field shifts (ca. $0.5 \mathrm{ppm}$ ) in the positions of both the $\mathrm{NCH}_{2}$ and the $\mathrm{OCH}_{2}$ methylene protons. No other regioisomer was found amongst the crude products. ${ }^{[62 \mathrm{~b}]}$ The regioselectivity of the isoxazole-forming NOAC reaction is thus on a par with that of the copper-promoted triazole click ligation procedures.



Scheme 5. Formation of doubly modified nucleoside derivatives by click-click NOAC chemistry in solution: i) $\mathrm{RCHNOH}$, chloramineT, $\mathrm{NaHCO}_{3}, \mathrm{EtOH} / \mathrm{H}_{2} \mathrm{O}, 1$ h, r.t. ${ }^{[62 \mathrm{~b}]}$

Conformation, configuration and conjugation are important features of modified oligonucleotides, and consequently site-specific reactivity is an important synthetic goal. There is particular interest in substituents at the $2^{\prime}$ position, which lock the ribose sugar in the $C 3^{\prime}$-endo conformation preferred by the RNAi intracellular ma-

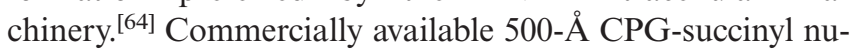
cleosides 9 [controlled pore glass, Eq. (2)] bearing click-addressable 2'-O-propargyl tags can serve as reactive partners in nitrile oxide/alkyne click chemistry ${ }^{[65]}$ The protocol involves mixing the desired oxime, as nitrile oxide precursor, and chloramine- $\mathrm{T}$ in aqueous EtOH in advance of exposure to the resin-supported nucleoside alkynes in an Eppendorf tube followed by agitation at room temperature. Formation of the active dipole by the prior mixing of the oxime and the oxidising agent is rapid; effectively it offers convenient access to "pre-formed" nitrile oxides. All four natural bases, with their standard protecting groups, can function as click partners under these conditions, and after reaction workup the newly generated isoxazoles are immune to the conditions required for base deprotection. Conjugation can be achieved both with aliphatic and with aryl nitrile oxides, but the rates of cycloaddition mirror the steric bulk of the dipoles. After time intervals ranging between $15 \mathrm{~min}$ and $16 \mathrm{~h}$ near quantitative conjugation can be achieved. HPLC analysis is a suitable tool to ascertain click efficiency and selectivity; typically the ligated adducts elute ca. 6 min later than the parent propargylated nucleosides.

In addition, derivitisation of CPG-succinyl nucleosides 9 by the chloramine-T-induced NOAC protocol can be directly performed in a DNA synthesis column, by conduction of the reaction with an agitated suspension of resinsupported reactant in an Eppendorf tube ${ }^{[65]}$; see Eq. (2). This augurs well for future commercial automation. Indeed, Carell and co-workers, starting from hydroxamoyl chloride precursors, have elegantly achieved nitrile oxide/styrene click conjugation in the DNA synthesizer. ${ }^{[66]}$ 


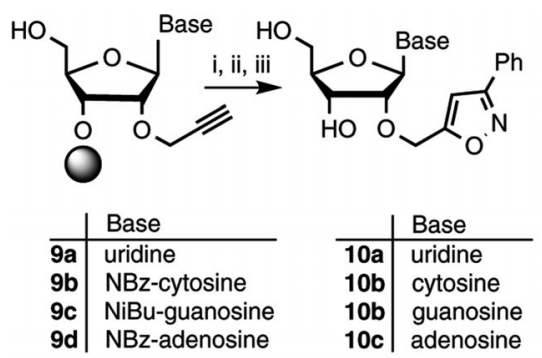

Ribonucleoside conjugates prepared by NOAC on the solid phase. Conditions: i) PhCHNOH, chloramine T, aq. EtOH, room temp., premix; ii) CPG-2'-O-propargylnucleosides, room temp., $15 \mathrm{~min}$; iii) cleavage and deprotection ${ }^{[65]}$

\subsection{Nucleotide Analogues}

To be valuable for synthesis of nucleotide conjugates the NOAC protocol must demonstrate compatibility with all components of these complex molecules: that is, the phosphodiester as well as the base and sugar components. Successful click conjugation to the synthetic nucleotide $\mathbf{1 4}$ (Scheme 6) provides confirmation that the phosphodiester moiety can tolerate the NOAC protocol mediated by chloramine-T. ${ }^{[62 \mathrm{~b}]}$ The alkyne-bearing nucleotide was prepared after coupling of the $5^{\prime}$-protected thymidine phosphoramidite 11 with the alkynyl alcohol 12 under standard conditions. Removal of the Dmt protecting group gave 14, which can, on exposure to chloramine-T in ethanolic $\mathrm{NaHCO}_{3}$, behave as a click partner with nitrile oxides generated in situ from the appropriate oximes. The one-pot reaction is fast at ambient temperature and is complete in under one hour. It compares favourably with the copper-catalysed for-

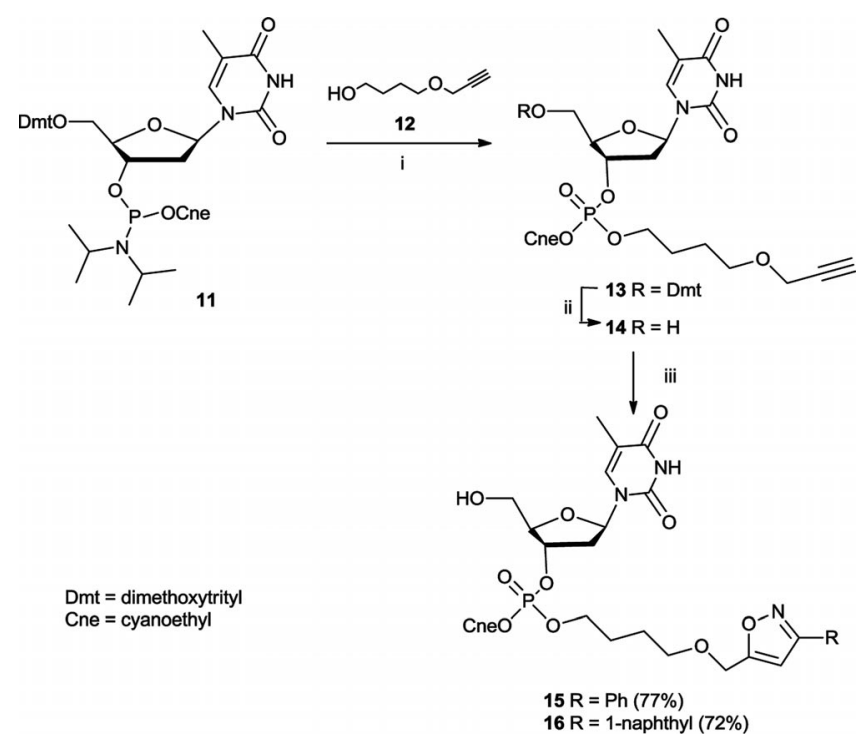

Scheme 6. Isoxazole-ligated synthetic dinucleotides prepared by NOAC in solution: i) anh. $\mathrm{CH}_{3} \mathrm{CN}, \mathrm{BMT}, \mathrm{Ar}, 0.5 \mathrm{~h}$, room temp., then oxidation; ii) DCA, $\mathrm{CH}_{2} \mathrm{Cl}_{2}$, room temp., $0.5 \mathrm{~h}$; iii) $\mathrm{RCHNOH}$, chloramine-T, $\mathrm{NaHCO}_{3}$, EtOH, 1 h, r.t. ${ }^{[62 \mathrm{~b}]}$ mation of triazole-linked dithymidines, which, although complete within 3 min under microwave activation conditions $\left(80^{\circ} \mathrm{C}, 300 \mathrm{~W}\right)$, require $24 \mathrm{~h}$ to reach ca. $40 \%$ completion at room temperature. ${ }^{[67]}$ The isoxazole-ligated nucleotides 15 and 16 were obtained in 70-80\% yields (Scheme 6). The characteristic resonance position of the isoxazole 4- $H$, in the $\delta=6.6 \mathrm{ppm}$ region, confirms the regioselectivity of the reactions.

Nucleotide analogues can also be prepared by resin-supported NOAC chemistry. ${ }^{[62 a, 65]}$ Model substrates, anchored to the resin through their 3 '-hydroxy groups and carrying terminal propargyl functionalities at their $5^{\prime}$-positions as the addressable tags (Scheme 7), can be derivitised by the click conjugation protocol, as illustrated for $\mathbf{1 7}$. The reaction involves direct addition of the oxime and chloramine$\mathrm{T}$ to a suspension of the resin-supported substrate in ethanolic $\mathrm{NaHCO}_{3}$ in an Eppendorf tube at room temperature. Formation of isoxazole conjugates such as $\mathbf{1 8}$ is complete in less than an hour. In comparison with analogous copperpromoted triazole ligation strategies the NOAC protocol is appealing in its simplicity; there is no need to exclude oxygen from the reaction vessel and the number and variety of reagents requiring optimisation are minimal.

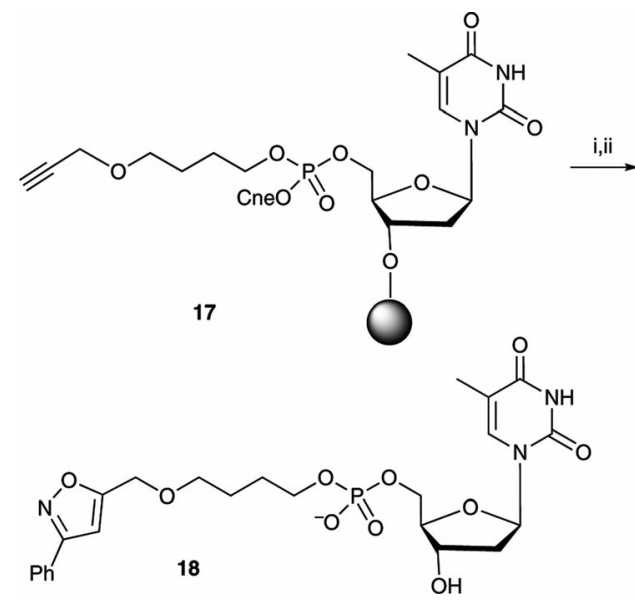

Scheme 7. Isoxazole-ligated synthetic dinucleotides prepared by NOAC with resin-supported alkyne nucleotides: i) $\mathrm{PhCHNOH}$, chloramine-T, $\mathrm{NaHCO}_{3}, \mathrm{EtOH}, 1 \mathrm{~h}$, room temp.; ii) cleavage and deprotection. ${ }^{62 \mathrm{~b}]}$

Positional control of oligonucleotide modification can be important; indeed, the delivery capabilities of siRNA conjugates are known to vary with the site of attachment. ${ }^{[68]} \mathrm{A}$ valuable feature of the NOAC protocol is its ability to provide designer conjugates; ligation can, if required, be achieved at either the $3^{\prime}$ - or the $5^{\prime}$-termini - or both - of an oligonucleotide substrate. Mono- and bis-ribonucleotide conjugates 22-24 (Figure 4) can be prepared by resin-supported mono-click, or bis-click-click, cycloadditions. The reactions can be carried out with nucleotides bearing terminal propargyl appendages either at the $3^{\prime}$-end of the molecule (19) or at the $5^{\prime}$-end (20), as well as at both the $3^{\prime}$ and the $5^{\prime}$-termini (21). For each of the transformations, the dipole was pre-formed in aqueous ethanol by treatment of the desired oxime with chloramine-T. This solution was 

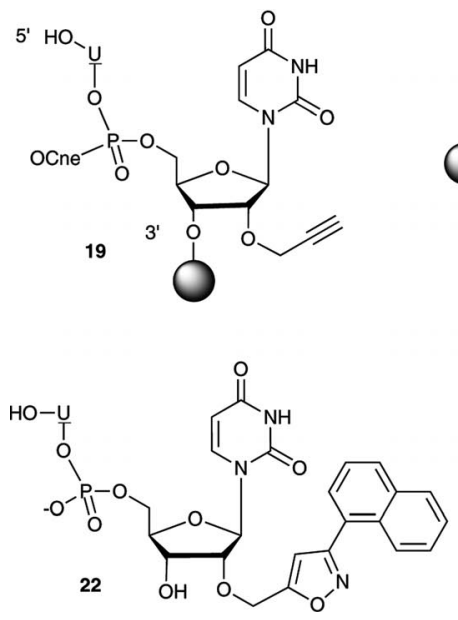
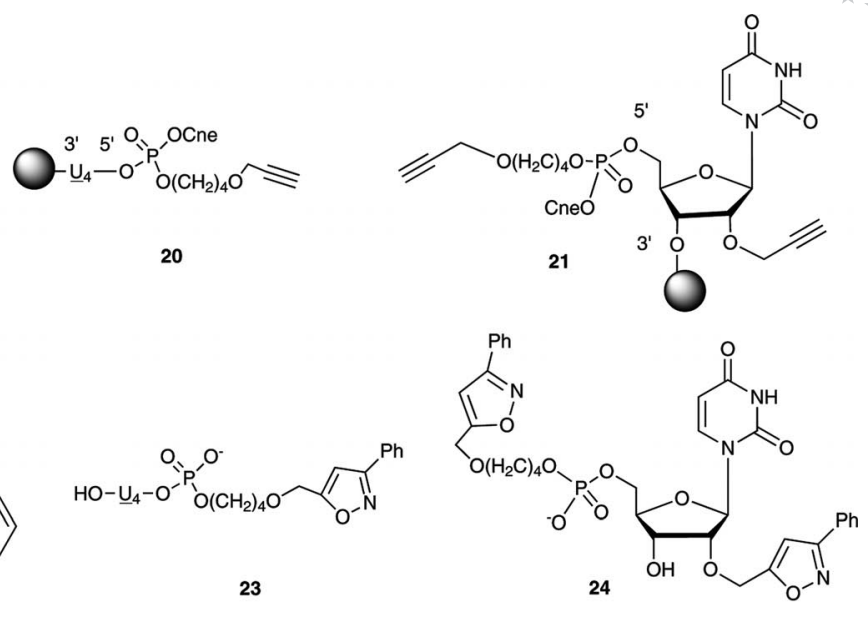

Figure 4. 2'-OMe oligoribonucleotide conjugates prepared by NOAC chemistry. ${ }^{[65]}$

subsequently transferred to an Eppendorf tube containing a suspension of the resin-supported oligonucleotide. In the formation of $\mathbf{2 2}$ it has been shown that 2'-O-propargyl moieties at the $3^{\prime}$-terminus of a dinucleotide can be addressed as click partners. Bulky dipoles react more slowly than those with lesser steric requirements (e.g., formation of the naphthyl-substituted cycloadduct requires $4 \mathrm{~h}$ to reach completion at room temperature; in direct comparison, formation of phenyl-substituted isoxazole conjugates requires only a 15 min reaction time). The formation of the tetramer $\mathbf{2 3}$ shows that the NOAC protocol can be used to conjugate oligonucleotides bearing terminal alkynes at their $5^{\prime}$-positions. High levels of cycloaddition efficiency are retained in the click-click product $\mathbf{2 4}$, confirming the robust nature of the protocol and suggesting future applications of NOAC in high-density functionalisation.

\subsection{Oligonucleotide Conjugates}

The need to provide chemically modified oligonucleotides for a range of biological and therapeutic applications has focused much synthetic effort in this direction. ${ }^{[69]}$ Pioneering research by the groups of Sella, ${ }^{[70]}$ Carell, ${ }^{[19 a, 66,71]}$ Brown, ${ }^{[72]}$ Morvan $^{[73]}$ and others ${ }^{[74]}$ offers an insight into the value of the CuAAC reaction for triazole-mediated DNA ligation, whereas we and others have developed NOAC chemistry as an effective, catalyst-free alternative. The acceptance of dipolar cycloaddition chemistry as a platform for oligonucleotide conjugation is reflected in the number of commercial sources offering diverse click reagents. In general, the marketed products involve azide dipoles, although a kit and a method for modifying in vitro synthesized RNA through click reactions including nitrile oxides and nitrones, as well as azides, is claimed. The kit consists of phosphoramidites or nucleoside triphosphates bearing one component of the click cycloaddition reaction together with a biomolecular probe with the complementary functionality. It claims the capability for modification of RNA either during or after the chemical synthesis, with potential advantages including low cost, easy operation, mild conditions, good modification effect and no influence on the bioactivity of RNA. ${ }^{[75]}$

\subsubsection{On-Resin Conjugation}

Nitrile oxide/alkyne cycloaddition chemistry promoted by chloramine-T can provide isoxazole-linked oligonucleotide conjugates. Propargyl-terminated, CPG-supported DNA substrates 25 (Scheme 8) can be ligated after reaction with nitrile oxides generated in situ. The reactions take place in aqueous ethanolic $\mathrm{NaHCO}_{3}$ at rates dependent on the steric demands of the dipole partners $(0.5$ to $18 \mathrm{~h})$. In all cases, product integrity is readily established by HPLC analysis and MALDI-TOF-MS data. Potential concerns relating to side reactions between the nitrile oxides and the nucleobases could be ruled out after a control experiment that returned CPG-supported decathymidylate 25a unchanged under the conditions of the NOAC reaction. ${ }^{[62 a]}$

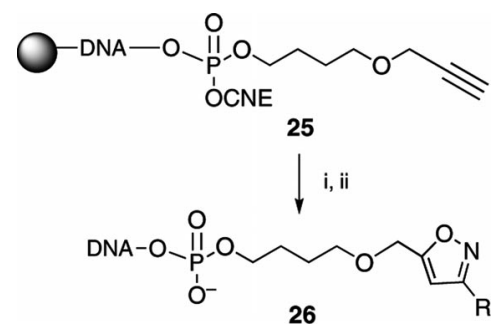

Scheme 8. Isoxazole conjugates prepared by NOAC with resin-supported alkyne-oligonucleotides: i) $\mathrm{RCHNOH}$, chloramine-T, $\mathrm{NaHCO}_{3}$, EtOH, room temp.; ii) cleavage and deprotection. $\mathrm{R}=$ phenyl, 1-naphthyl, 9-anthracenyl. a) DNA $=\mathrm{T}_{10}$. b) $\mathrm{DNA}=5^{\prime}$ TCG CAC ACA CGC 3'. ${ }^{[62 a]}$

\subsubsection{Click Prior to Conjugation}

Prospective problems of operational efficiency or functional group tolerance in the preparation of isoxazole-ligated oligonucleotides can be avoided by coupling of phosphoramidite building blocks already bearing the moiety to be conjugated. Although click-generated designer triazole phosphoramidites have been prepared by CuAAC chemistry, ${ }^{[76]}$ isoxazole analogues are virtually unknown. ${ }^{[77]}$ The 
isoxazole building blocks 28 (Scheme 9), with pendant hydroxy functionalities, can be prepared by the NOAC protocol with induction by chloramine-T; the reactions involve in situ dipole generation from the oximes $\mathbf{2 7}$ and trapping with phenyl propargyl ether. The click-generated products can be converted into the phosphoramidites $\mathbf{2 9}$, which can in turn be employed as monomers for either manual or automated solid-phase coupling to the $5^{\prime}$-terminus of a growing oligonucleotide (Scheme 9). ${ }^{[78]}$ Yields of conjugates 30, derived from isoxazoles generated off-resin, compare favourably with those obtained for similar conjugates con-

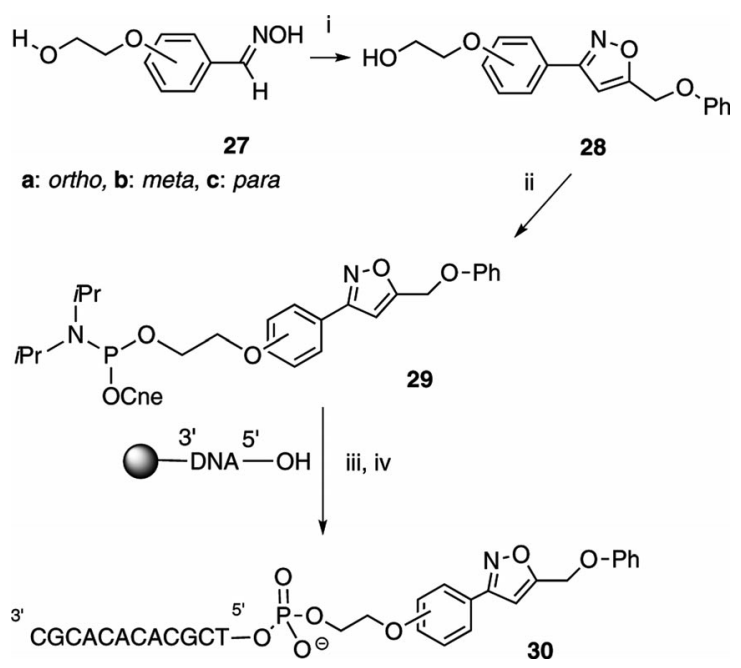

Scheme 9. NOAC induced by chloramine-T, isoxazole phosphoramidite formation and preparation of DNA conjugates: i) chloramine- $\mathrm{T}, \mathrm{EtOH} / \mathrm{H}_{2} \mathrm{O}, \mathrm{HC} \equiv \mathrm{CCH}_{2} \mathrm{OPh}$, room temp., $18 \mathrm{~h}$; ii) BMT, $\left(i \mathrm{Pr}_{2} \mathrm{~N}\right)_{2} \mathrm{POCH}_{2} \mathrm{CH}_{2} \mathrm{CN},\left(i \mathrm{Pr}_{2}\right) \mathrm{NH}$, room temp., MeCN, $30 \mathrm{~min}$; iii) $\mathrm{BMT},\left(i \mathrm{Pr}_{2}\right) \mathrm{NH}$, room temp., $\mathrm{MeCN}, 30 \mathrm{~min}$; iv) oxidation, cleavage and deprotection. ${ }^{[78]}$

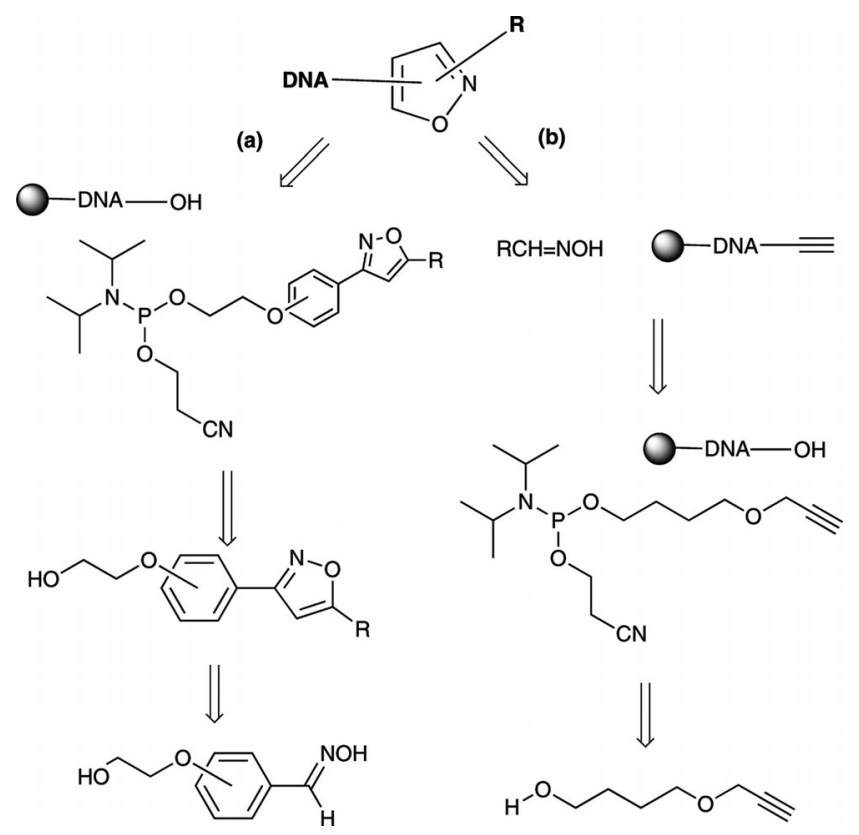

Figure 5. Retrosynthetic routes to oligonucleotide conjugates utilising a) off-resin, ${ }^{[78]}$ and b) on-resin ${ }^{[62 a]}$ NOAC chemistry. structed by on-resin NOAC chemistry with alkyne-modified DNA substrates (Figure 5, path b). ${ }^{[62 a]}$

\section{Strain-Promoted Cycloadditions of Nitrile Oxides (Nitrones) and Alkynes}

The first examples of strain-promoted nitrile oxide cycloaddition involved norbornene-modified DNA substrates. ${ }^{[79]}$ The strained alkene, introduced into a growing DNA strand by way of a modified thymidine phosphoramidite, is suited to cycloaddition with a variety of nitrile oxides generated in situ either from hydroxamoyl chlorides or directly by treatment of the parent oxime with NCS. The success of the reaction forming the 2-isoxazoline - see Eq. (3) - is based on the release of about $6 \mathrm{kcal} \mathrm{mol}^{-1}$ of angular strain energy of the norbornene ring system. An attractive feature of this reaction is its applicability to automation on a DNA synthesiser; however, although being exo-selective it proceeds without regioselectivity. ${ }^{[79]}$

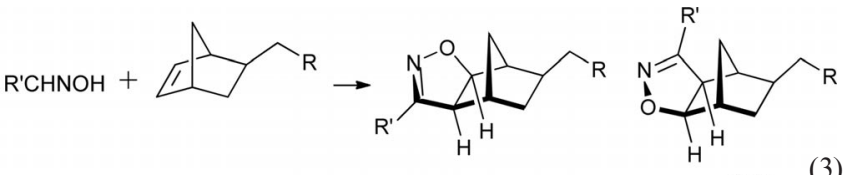

Strain-promoted cycloaddition between alkens and nitrile oxides. ${ }^{[79]}$

A number of groups have capitalised on the potential, pioneered by Bertozzi and co-workers, ${ }^{[35 a]}$ of cyclooctynes as highly reactive dipolarophiles. With these substrates, which release almost $18 \mathrm{kcalmol}^{-1}$ of strain energy during cycloaddition, the requirement for a (cytotoxic) catalyst to promote azide/alkyne cycloaddition is redundant and the azide/alkyne reaction earns the revered status of biocompatibility. Although numerous applications with living systems have been reported, ${ }^{[36 \mathrm{~d}, 40,80]}$ this chemistry has more recently been exploited in the nucleic acids space. Examples include room-temperature labelling of DIBO-modified (dibenzocyclooctyne-modified) oligonucleotides either at the $5^{\prime}$ - or the $3^{\prime}$-termini with fluorescent or oligosaccharide groups; the same handle is exploited in formation of $5^{\prime}$ labelled DNA- or RNA-peptidic or sugar conjugates ${ }^{[37 c, 81]}$ and in templated DNA ligation. ${ }^{[72 b]}$ In their reactions with

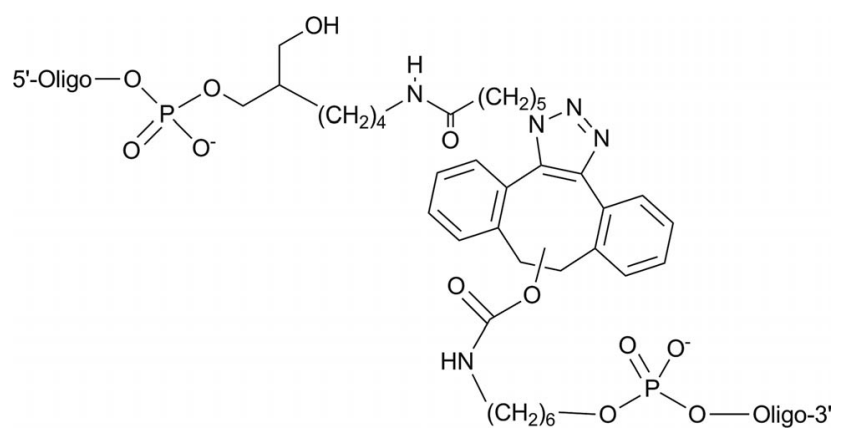

Figure 6. DNA ligation product formed by SPAAC chemistry. ${ }^{[72 b]}$ For clarity only one regiosiomer of the triazole conjugates is shown. 
azides, dibenzocyclooctynes are found to be more reactive cycloaddition partners than monocyclic octynes; formation of the templated DNA ligation product shown in Figure 6 is thus complete within the first minute of exposure. Significantly, it is observed that $\mathrm{Cu}(1)$ strongly inhibits the SPAAC, probably as a result of complexation to the cyclic alkyne. ${ }^{[72 b]}$

\subsection{Click Conjugation to Monocyclic Alkynes}

Complex syntheses and unfavourable kinetics with bulky dipoles can limit the preference for cyclooctynes of enhanced reactivity (e.g., diaryl or fluorinated variants) as azide click partners. Recently it has been remarked that the steric requirement of the conjugating moiety limits the extent of peptide polymer conjugation. ${ }^{[82]}$ Simple unactivated monocyclic octynes with reduced lipophilicity and limited steric bulk could therefore be valuable. The ensuing adducts ought to have superior aqueous solubilities and reduced tendencies to interact with hydrophobic biomolecules, characteristics valued in drug delivery, biomedicine and imaging. For these reasons, our group were interested in developing protocols for strain-promoted conjugation to oligonucleotides bearing monocyclic octyne moieties. The range of commercially available azide dipoles and the widespread adoption of click imaging by non-chemists inspired us to explore azides as well as nitrile oxide dipoles.

\subsubsection{Click Conjugation between Azides and Monocyclic Alkynes}

Resin-supported oligonucleotide cyclooctynes such as $\mathbf{3 1}$ (Figure 7), constructed from the new phosphoramidite 32, were found to be resilient to the standard conditions of solid-phase oligonucleotide synthesis. Click cycloaddition to the monocyclic strained alkyne can be achieved at room temperature with use of 20 equivalents of azide, at an effective concentration of ca. $140 \mathrm{~mm}, .{ }^{[83]}$ The reaction medium is dictated by dipole solubility and the time required for formation of the triazole conjugates $33(20 \mathrm{~min} / 16 \mathrm{~h})$ is directly influenced by the size of the dipole. The range of azide substrates includes benzyl, cinnamyl, glucose, coumarin, biotin and cholesterol azides (Figure 8). Potential drug delivery applications ${ }^{[74 a]}$ make conjugation to cholesteryl dipoles significant; earlier syntheses of cholesterol conjugates by CuAAC either at the monomer level, prior to oligonucleotide synthesis, or directly to a resin-supported oligonucleotide-alkyne required microwave assistance $\left(60{ }^{\circ} \mathrm{C}\right.$, $45 \mathrm{~min}) .{ }^{[74 a, 84]}$

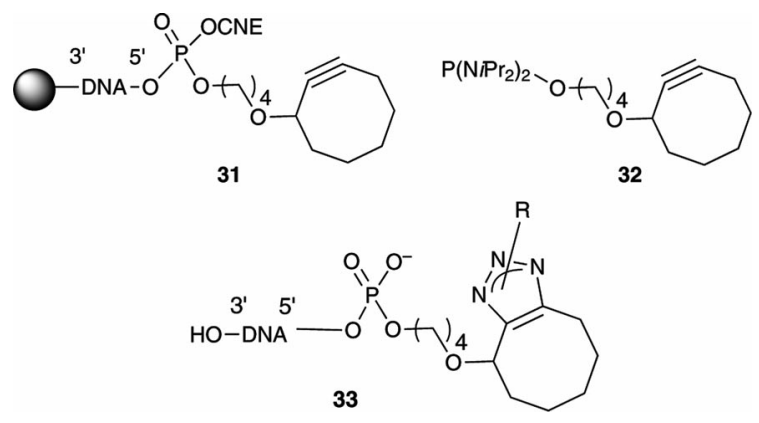

Figure 7. Phosphoramidites, DNA-cyclooctynes and triazoleligated oligonucleotides prepared by SPAAC. ${ }^{[83]}$

Despite the obvious attractions of solid-phase syntheses (SPS), the precondition that the final products be inert to the cleavage/deprotection protocols can be prohibitive. To allow for such eventualities and to claim full versatility for SPAAC with monocyclic cyclooctynes a solution-phase synthesis of the triazole-ligated fluorescein conjugate 34 (Figure 9) has been demonstrated. ${ }^{[83]}$ The observed propensity of the fluorescein core to lactonise under the basic conditions required for cleavage of the conjugate from the resin precludes its synthesis by the resin-supported approach. An aqueous solution of DNA-cyclooctyne, obtained from 31 after deprotection and cleavage from the resin, can thus be conjugated after exposure to an aqueous DMF solution of fluorescein azide. The reaction requires agitation at room temperature overnight. Optimum rates of conversion to the conjugate $(\approx 80 \%)$ require a doubling of the number of azide equivalents (40 equiv.) relative to that required for analogous solid-phase reactions.



Figure 8. Selected azide click partners for SPAAC with DNA-cyclooctyne 31. ${ }^{[83]}$ 


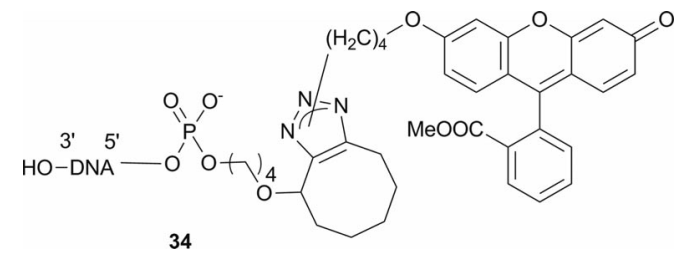

Figure 9. Triazole-ligated DNA conjugate prepared in solution phase by SPAAC. ${ }^{[83]}$

\subsubsection{Click Conjugation between Nitrile Oxides and Monocyclic Alkynes}

Recent studies on the relative reactivities of nitrile oxides, nitrones and diazocarbonyl derivatives as alternatives to azide dipoles in reaction with cyclooctynes suggest inferior kinetics (with respect to azides) for diazocarbonyl moieties and superior reactivities for strain-promoted alkyne/nitrile oxide cycloaddition (SPANOC). ${ }^{[43 b, 56]}$ Theoretical studies concluded that bond angle and strain release, together with the attainment of aromatic status in the isoxazole product, are the driving forces for the reaction. ${ }^{[85]}$ The relative reactivities of nitrones are closely related to their structures, with cyclic nitrones being the most effective dipoles. ${ }^{[43 b, 86]}$ Interestingly, in spite of their modest reactivities, peptides bearing nitrone moieties can still be trapped with dibenzocyclooctyne (DIBO) derivatives at rates sufficiently high to permit selective tagging of proteins and complex carbohydrates. ${ }^{[87]}$ The rate constant for $[3+2]$ addition of bicyclo[6.1.0]nonyne (BCN) 35 (Figure 10) to benzonitrile oxide $\left(1.8 \mathrm{M}^{-1} \mathrm{~s}^{-1}\right)$ was found to be greater by a factor of 10 than that observed for the corresponding reaction with benzyl azide. ${ }^{[56]}$ Similar results were observed with DIBO; benzonitrile oxide (generated in situ from the hydroxamoyl chloride) reacted about 60 times more rapidly than benzyl azide (Scheme 10). Oximation, oxidation and cycloaddition can be streamlined as a one-pot reaction, which is especially attractive from an experimental perspective. The potential of the telescopic process, which is based on on keeping the dibenzocycloalkyne separate from the hydroxylamine, is evident from its ability to yield biotin-labelled carbohydrates and sialic-acid-labelled glycoproteins (Scheme 11). ${ }^{[43 \mathrm{~b}]}$

Isoxazole nucleoside conjugate 36 (Figure 10) can be formed by PIFA-induced nitrile oxide/alkyne cycloaddition to $\mathrm{BCN} 35$. The reaction, which occurs within minutes in aqueous methanol under ambient conditions, suggests that this approach can be valuable for applications requiring derivatisation of unprotected nucleosides. ${ }^{[56]}$ It is well known that nitrile oxides have a tendency to dimerise in the absence of a suitable reaction partner, but a further word of caution with regard to the use of hypervalent iodine reagents is prompted by the observation that aliphatic or aromatic aldoximes, in the presence of (diacetoxyiodo)benzene (DIB) or [hydroxy(tosyloxy)iodo]benzene (HTIB) can yield, rather than the expected nitrile oxides (or their dimerization products), the corresponding $\mathrm{N}$-acetoxy and $\mathrm{N}$-hydroxyamides. ${ }^{[88]}$
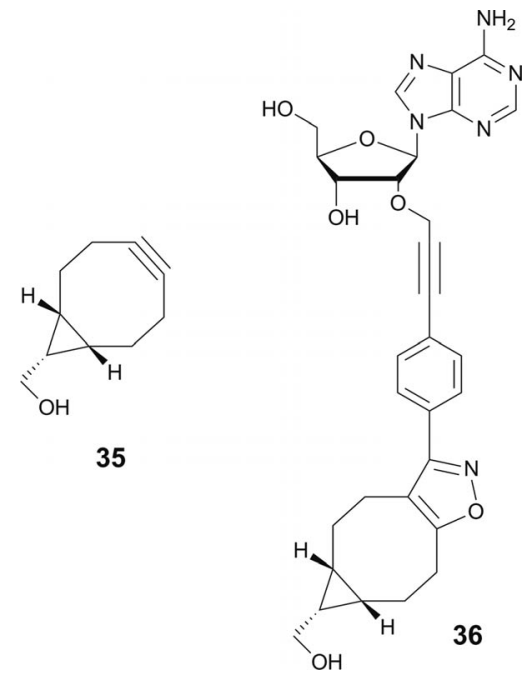

Figure 10. Bicyclo[6.1.0]nonyne (BCN) 35 and nucleoside analogue 36, formed by strain-promoted nitrile oxide/alkyne cycloaddition (SPNOAC). ${ }^{[56]}$

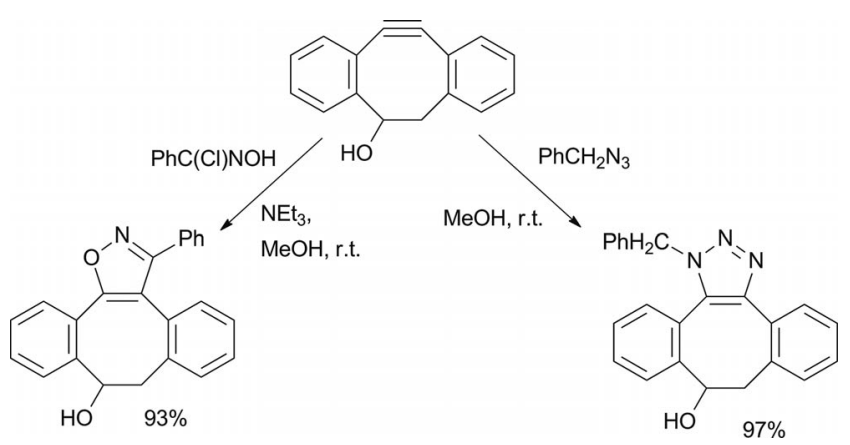

Scheme 10. Cycloaddition between dibenzocyclooctynol (DIBO) and benzyl azide or benzonitrile oxide dipoles. ${ }^{[43 b]}$

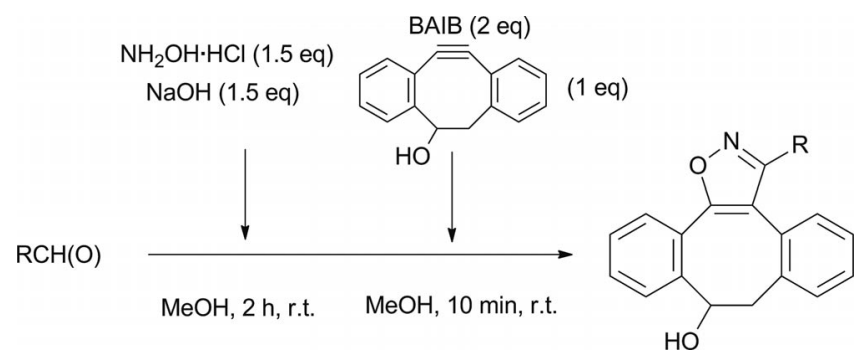

Scheme 11. Telescopic one-pot SPNOAC; BAIB = bis(acetoxy)iodobenzene. ${ }^{[43 \mathrm{~b}]}$

The sluggish reactivities of monocyclic cyclooctynes afford an opportunity to showcase the attributes of nitrile oxides as dipoles. Strain-promoted cyclooctyne/nitrile oxide click cycloadditions between the resin-supported DNA-cyclooctyne 31 (Figure 7) and a range of nitrile oxides generated in situ can be achieved in near-quantitative yields within $10 \mathrm{~min}$ at room temperature. Reaction conditions are straightforward: a solution of the nitrile oxide dipole, generated by pre-mixing the parent oximes and chloramine-T (in a 1:1 ratio), is added to a suspension of the resin-supported oligonucleotide in an Eppendorf tube. Solvent choice - 
EtOH, DMF, water or mixtures of the same - is dictated by dipole solubility issues. As expected, the selectivity observed in addition to the terminal alkyne is sacrificed with the cyclic substrate. The regioisomeric isoxazole-DNA conjugates $37 / 38$ (Figure 11) represent the first examples of resin-supported DNA ligation by exploitation of a monocyclic alkyne as click partner. On comparison with similar acyclic substrates (e.g., 25) it is clear from the reduction in activation barrier associated with the cyclic alkyne that the click reaction can be executed with a much reduced concentration of dipole. ${ }^{[89]}$ The reaction is tolerant of nitrile oxides bearing bulky aryl groups, including pyrenyl groups, and is also compatible with the hydroxy functional group, which could represent a useful handle for further modification of DNA. Finally, formation of the coumarin conjugates 39 (only one regioisomer shown) suggests that this method can be used to provide fluorescently labelled conjugates.

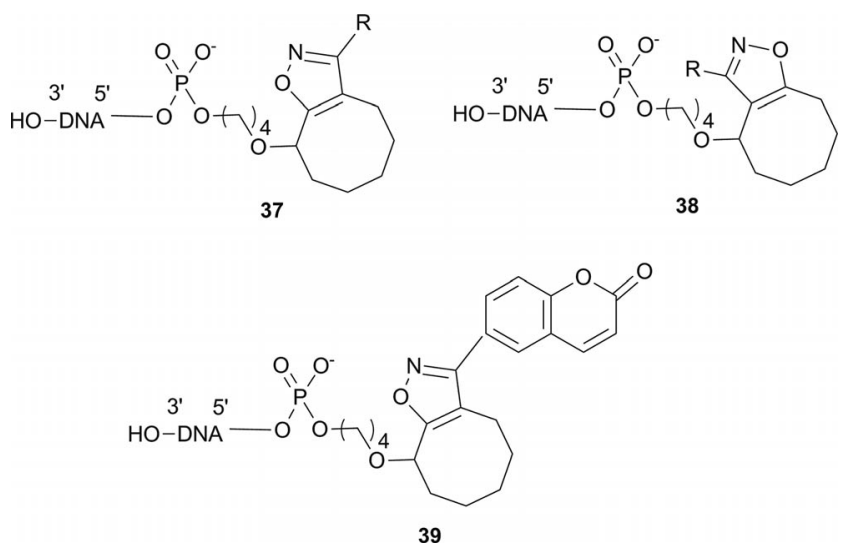

Figure 11. Isoxazole-ligated DNA conjugates prepared by SPANOC. R = phenyl, 1-naphthyl, 2-fluorophenyl, 1-pyrenyl, 2-(2hydroxyethoxy)phenyl. ${ }^{[89]}$ For purposes of clarity, only one regiosiomeric isoxazole will be drawn from this point forward.

\subsection{Click-Click and Click-Clunk Cycloadditions - Multiply Functionalised Substrates}

Complex molecular architectures have been assembled by multiple click reactions (click/click) on a single substrate (e.g., cross-linking), by stepwise or bisclick reactions or high-density functionalisation of DNA molecules. ${ }^{[19 a, 70 b, 90]}$

More complex architectures have been achieved by modulation of a range of click chemistries (click/clunk). ${ }^{[10]}$ Successive chemoselective ligations, either stepwise or one-pot, avoid tedious purification procedures and generally furnish high yields of products. For these reasons substrates bearing combinations of orthogonal "clickable" groups have been designed; examples of complementary reactivity include oxime bond formation, copper(I)-mediated alkyne/azide cycloaddition and thioether bond formation, CuAAC/radical coupling reactions SPAAC/thiol ene photochemistry and epoxy-amine/thiol-ene coupling. ${ }^{[91]}$ Threefold orthogonality has been demonstrated with SPAAC, Diels-Alder and thiol ene chemistries in designer decorated nanoparticles. ${ }^{[92]}$ Iterative click reactions furnishing doubly and triply triazole- decorated structures have been formed by copper-free and/ or copper-mediated azide/alkyne cycloadditions; ${ }^{[25]}$ substrates include representatives bearing one free and a variety of orthogonally protected alkyne residues, ${ }^{[71,93]}$ one azide and one alkyne functionality ${ }^{[94]}$ and a terminal and a cyclic alkyne moiety, as well as those carrying various combinations of free alkynes, protected alkynes and cyclic alkynes. ${ }^{[95]}$

Orthogonal, azide/alkyne and nitrile oxide/alkene click cycloaddition chemistries can be applied to high-density DNA functionalisation. DNA strands (ca. 300 base pairs) richly decorated with styrene and propargyl functionalities can undergo rapid CuAAC reactions upon addition of azido sugars, together with a $\mathrm{Cu}(1)$ catalyst, to form intermediate triazole-ligated sugar-DNA conjugates. After purification (by ethanol precipitation), the styrene units, which are inert to azides, can then by trapped by the more reactive nitrile oxide dipole (Scheme 12). ${ }^{[66]}$

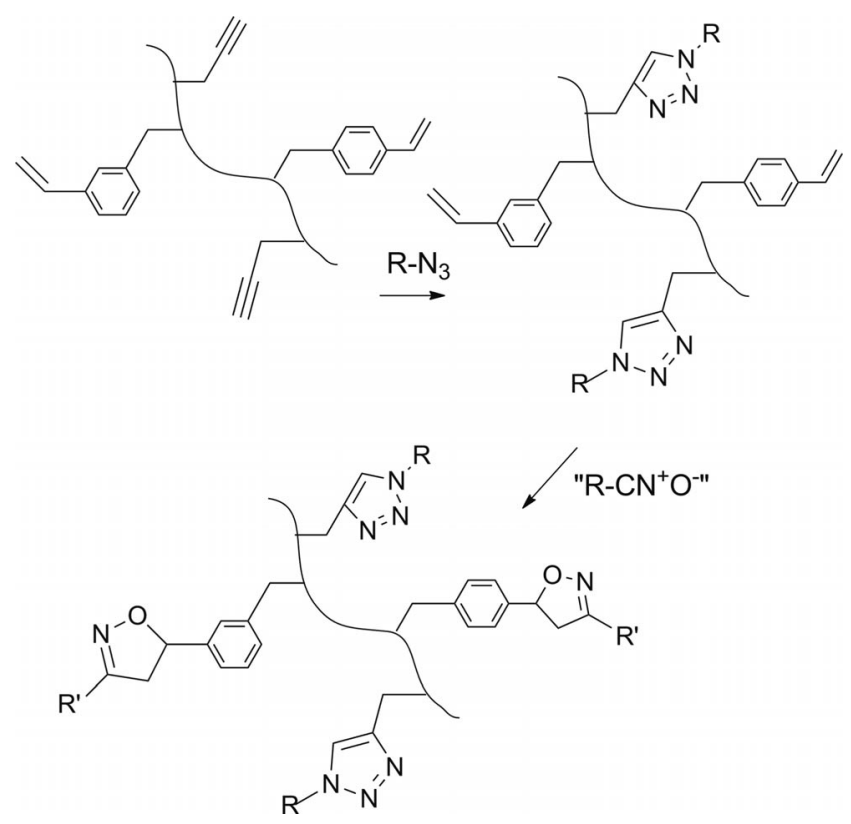

Scheme 12. Click-clunk postsynthetic DNA functionalisation by copper-promoted and copper-free cycloadditions. ${ }^{[66]}$

\section{Applications in Supramolecular and Polymer Chemistry}

In polymer chemistry, click reactions are valued both for polymer growth and for modification of the polymer after the polymerisation process. ${ }^{[2]}$ Traditional approaches to designer polymers have involved controlled incorporation of functional moieties. ${ }^{[96]}$ Modification of the polymeric frame has obvious attractions, however, and the ability to control architecture and degree of functionalisation by click-type chemistry is very attractive. ${ }^{[2,11 a]}$ The limitations of the copper-promoted reaction, and the masked synthetic potential of the isoxazole ring, prompted us and others to explore the potential of nitrile oxides as click cycloaddition partners 
for formation of supramolecular constructs or polymers of predefined structure.

\subsection{NOAC in the Construction of Supramolecular and Polymer Architectures}

An early reference to nitrile oxides as clickable functionalities appears in patent literature describing multivalent dendrimers as pharmaceutical or diagnostic agents, encompassing peptides, oligopeptides, proteins and carbohydrates. ${ }^{[97]}$ Rotaxanes can be formed by click end-capping reactions between nitrile oxides and alkyne-bearing pseudorotaxane substrates (Scheme 13) ${ }^{\left[{ }^{[8]}\right]}$ For these applications superior results are found with preformed stable dipoles; the click capping reactions are distinctly less successful when in situ dipole generation is attempted with hydroxamoyl chlorides and $\mathrm{NEt}_{3}, \mathrm{AgOTf}$ or MS (4 $\AA$ ). Isoxazole-containing [2] rotaxanes (Scheme 13) can be obtained in good yields after reactions either at room temperature (ca. $1 \mathrm{~d}$ ) or at reflux in $\mathrm{CH}_{2} \mathrm{Cl}_{2}$ (ca. 2 h) or 1,2-dichloroethane (ca. $20 \mathrm{~min}$ ). At higher temperatures there is a slight sacrifice in yield attributed to entropy-driven dissociation of the pseudorotaxane.

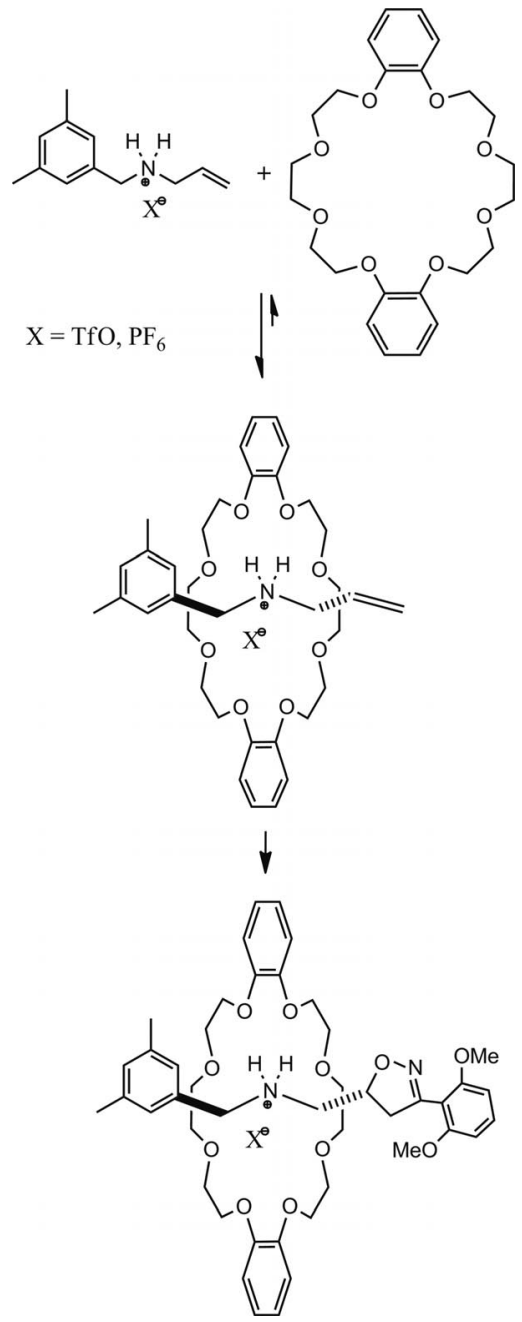

Scheme 13. Click end-capped [2]rotaxanes prepared by NOAC. ${ }^{[98]}$
Click polymerisation between homo-ditopic nitrile oxides and bifunctional terminal olefinic and acetylenic monomers is a simple, yet powerful tool suited to applications in materials chemistry. ${ }^{[99]}$ Taketa and co-workers show in their work (Scheme 14) that molecular sieves (4 Å) can function both as base and as dehydrating agent for in situ generation of bisnitrile oxides from hydroxamoyl dichloride precursors. Polycycloadditions can be executed with diynes; more recently it has been shown that bisnitriles are also suitable polymerisation partners. ${ }^{[99]}$ Polymerisation is achieved at $80^{\circ} \mathrm{C}$ in DMF with a $1: 1$ ratio of reactants. The high degree of homogeneity of the polyisoxazole products is attributed to the regiochemical preference for formation of the 3,5-disubstituted isoxazole: polydispersity indexes are typically between 1.3 and 2.0. The isoxazole ring can be envisaged as masking a range of functionalities including aldol, diketone, amino alcohol etc. and Takata and coworkers have begun to unveil this potential, demonstrating controlled or complete reduction to poly( $\beta$-aminoenones) or $\operatorname{poly}\left(\beta\right.$-amino alcohols). ${ }^{[99]}$

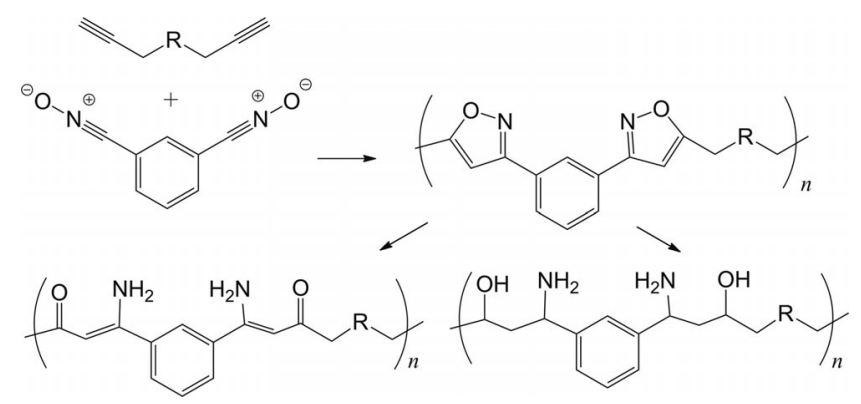

Scheme 14. Polymer formation by NOAC between bis(nitrile oxides) and diynes and transformation of the polyisoxazole by controlled and full reduction. ${ }^{[99]}$

In a further elaboration of macromolecular architecture it has been shown that trifunctional aromatic nitrile oxides can behave as crosslinking agents. Dipole formation from the trioximes is facilitated by treatment of the parent oximes either with $\mathrm{N}$-chlorosuccinimide and $\mathrm{Et}_{3} \mathrm{~N}$ or with bromine and $\mathrm{NaOH} \cdot{ }^{[100]}$

\subsection{Post-Synthetic Click Modification of Polymers by NOAC}

Chain-end polymer functionalization can be achieved through NOAC chemistry. Alkyne-functionalised biocompatible telechelic copolymers $\mathbf{4 0}$ and $\mathbf{4 1}$ (Figure 12) succumb to the chloramine-T-induced NOAC protocol. The click products, arising from reaction with aryl nitrile oxides, formed in situ from the parent oximes, are illustrated in Figure 12 . The reactions are easily executed at room temperature in aqueous ethanol in the presence of $\mathrm{NaHCO}_{3}$. Generally, cycloaddition is complete in $16 \mathrm{~h}$, although if progress is poor - with sterically encumbered dipoles, for example - repetition of the dose of oxime and chloramine$\mathrm{T}$ after $12 \mathrm{~h}$ enhances the conversion. Purification of the conjugated polymeric products from excess reagents can be 

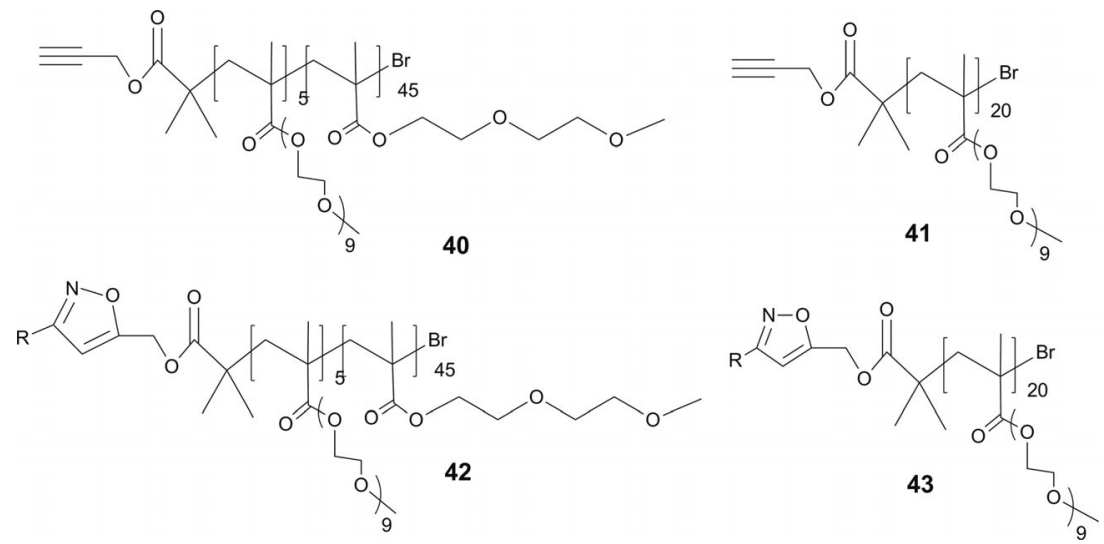

Figure 12. Chain-end polymer modification by post-synthetic NOAC modification at the $\alpha$-terminus; R = phenyl, 2-fluorophenyl, 2 nitrophenyl, 1-naphthyl, 9-anthracenyl. ${ }^{[101 \mathrm{a}]}$

easily achieved by dialysis. The near quantitative reaction was confirmed as highly regioselective by ${ }^{1} \mathrm{H}$ NMR spectroscopic analysis. Compatibility of the NOAC protocol with the inherent polymer structure is confirmed by size exclusion chromatography (SEC), turbidity and cloud point measurements, which show the click functionalized polymers $\mathbf{4 2}$ and $\mathbf{4 3}$ to have the same molecular weights and molecular weight distributions prior and subsequent to click modification. ${ }^{[101 \mathrm{a}]}$

Copper-free NOAC and copper-promoted CuAAC cycloadditions can be combined in a new embodiment of click-clunk cycloaddition chemistry for post-synthetic modification of polymer substrates at their $\alpha$ - and $\omega$-termini. ${ }^{[101 b]}$ The potential of this chemistry is demonstrated with model, heterotelechelic, polystyrene polymers 44 (Scheme 15), bearing $\alpha$-alkyne and $\omega$-azido end-groups. The poor kinetics of the azide/alkyne cycloaddition in the absence of a catalyst permit orthogonal modification of un- symmetrical substrates bearing these functionalities. Initial exposure of $\mathbf{4 4}$ to the nitrile oxide (generated in situ) efficiently traps the alkyne moiety in a NOAC reaction. The active dipole for the NOAC can be formed in the presence of the polymer by $\mathrm{NEt}_{3}$-induced dehydrochlorination of the precursor hydroxyamoyl chloride. During the formation of 45 the azide dipole remains inert. After purification, by simple precipitation from methanol, the cycloaddition potential of the azide moiety of the polymeric intermediate $\mathbf{4 5}$ can be unlocked. Addition of an external alkyne together with a copper catalyst yields the doubly modified polymers 46. Both the isoxazole- and the triazole-forming reactions proceed with excellent regioselectivities and chemical yields. The incorporation of a fluorescein moiety in $\mathbf{4 7}$ suggests possible application in polymer labelling for biomedical studies. Molecular weight and molecular weight distribution measurements of the click-clunk polymers $\mathbf{4 6}$ mirror those of the precursors, suggesting that both the NOAC

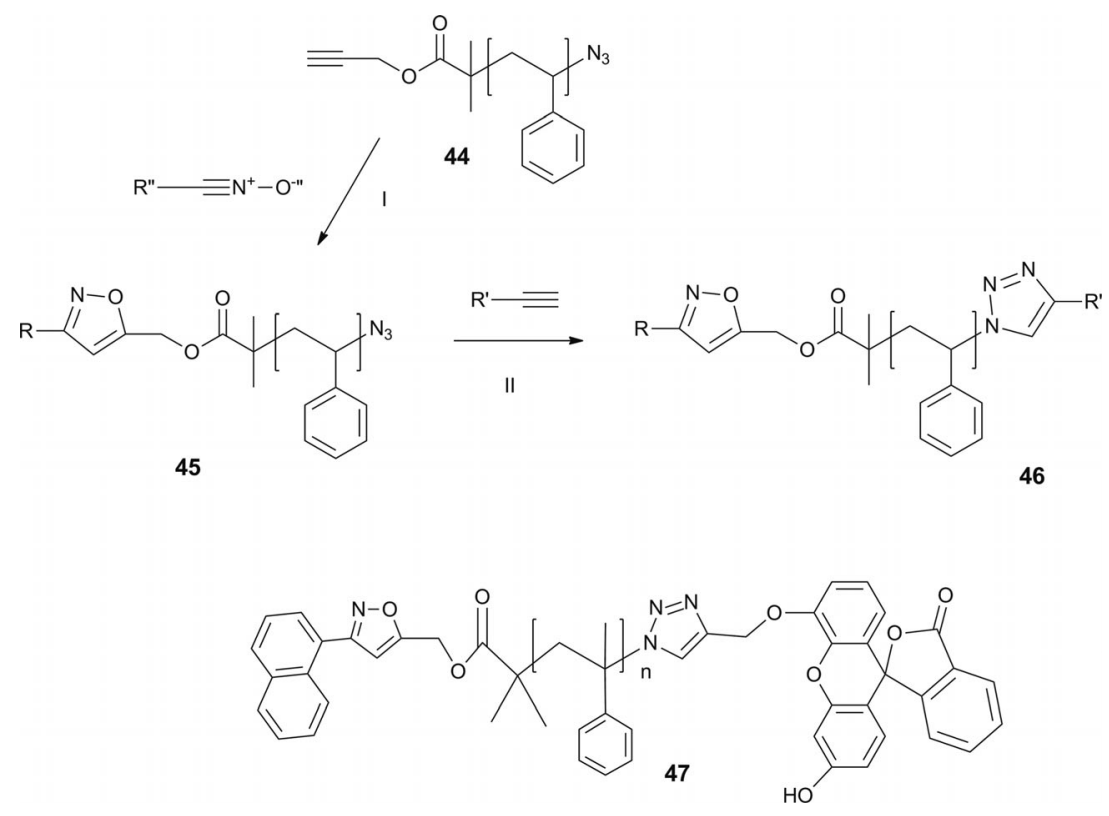

Scheme 15. Click-clunk end-capping of $\alpha$-alkyne- $\omega$-azidopolystyrene polymers by complementary NOAC and CuAAC chemistries; $\mathrm{R}=$ phenyl, 1-naphthyl; $\mathrm{R}^{\prime}=\mathrm{CH}_{2} \mathrm{OH}, \mathrm{C}(\mathrm{O}) \mathrm{CH}_{3} \cdot{ }^{[101 b]}$ 


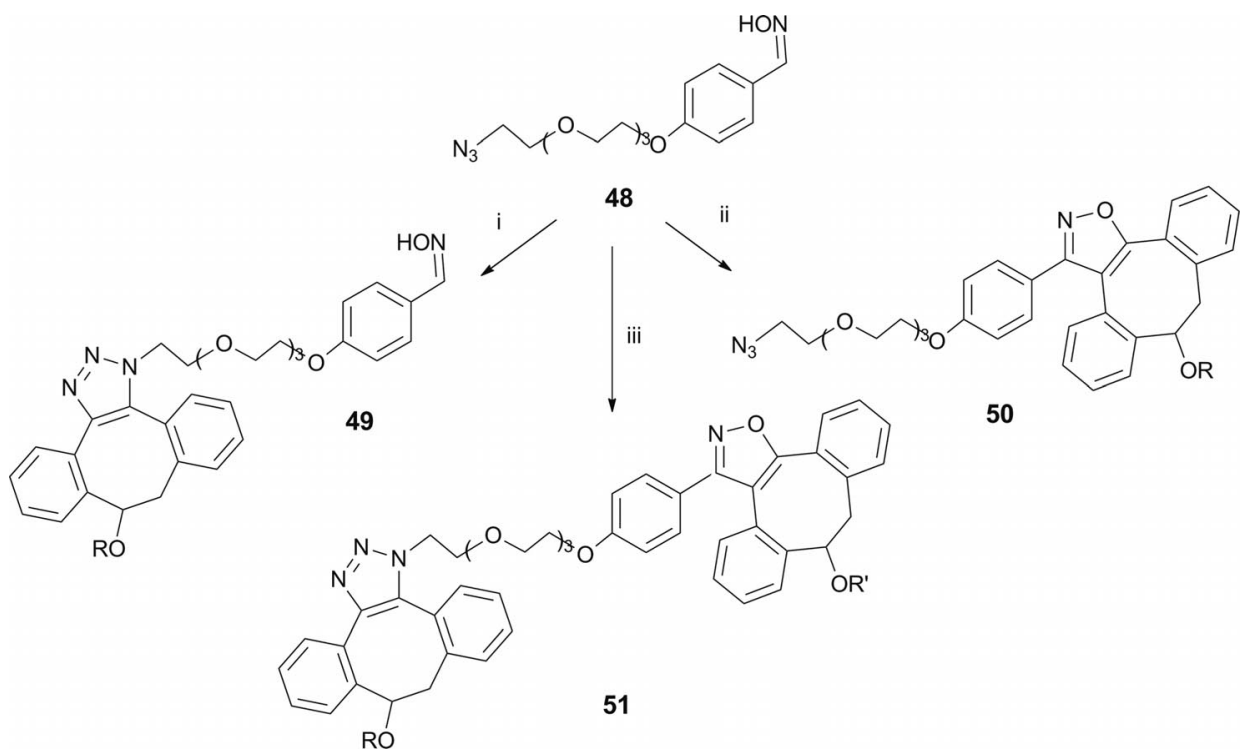

Scheme 16. Control of click, clunk or click-clunk functionalization by choice of reaction conditions: i) dibenzocyclooctyne, MeOH, room temp.; ii) $\mathrm{BAIB}, \mathrm{MeOH}$, room temp.; iii) dibenzocyclooctyne ( $\mathrm{R}$ substuituent), $\mathrm{MeOH}$ room temp., then dibenzocyclooctyne ( $\mathrm{R}^{\prime}$ substuituent), BIAB. ${ }^{[43 b]}$

and the CuAAC chemistries are suited to post-synthetic polymer modification.

In another manifestation of the orthogonality of azides and nitrile oxides, Sanders and co-workers have shown that, with judicious choice of reaction conditions, controlled modification of bifunctional azidooxime substrates 48 is possible (Scheme 16). If the reactants are simply mixed in $\mathrm{MeOH}$ at room temperature a triazole-forming SPAAC results in formation of 49. However, in the presence of BAIB, the latent oxime rapidly provides a nitrile oxide with which the azide is insufficiently reactive to compete for the dipolarophile and an isoxazole forms through a SPANOC reaction, to afford 50. Sequential azide/nitrile oxide cycloadditions allow the creation of multifunctional products 51 in one-pot fashion simply by controlling the order of addition of the reagents. ${ }^{[43 \mathrm{~b}]}$

\section{Conclusions}

This review has covered some of the shortcomings of the azide/alkyne click reaction and overviewed the most commonly applied solutions to the problems associated with copper toxicity and residual catalyst ions. It proposes that nitrile oxide/alkyne cycloaddition (NOAC) reactions and strain-promoted nitrile oxide/alkyne cycloadditions (SPNOACs) can be likened to "molecular adhesives" capable of weaving components together in a catalyst-free environment, without the need for any specialised reaction setup. Although the propensity of nitrile oxides to get involved in side reactions, including dimerisation and nucleophilic attack, might have discouraged some researchers from studying their potential as a conjugation methodology, the kinetics of the nitrile oxide alkyne/cycloaddition can confer favoured status on this dipole and justify application of the term "superglue" to the NOAC reaction. This article fo- cuses primarily on applications in the spheres of nucleic acid and polymer chemistry, but it cannot be doubted that applications of nitrile oxide click cycloadditions will continue to emerge across the broad field of conjugation chemistry. It can be concluded that NOAC holds great promise as a premier player in the click toolbox and will certainly contribute to future creative advances in chemical biology as well as in materials science.

\section{Acknowledgments}

Financial support from the Science Foundation of Ireland (Programme code 05/PICA/B838) is acknowledged.

[1] H. C. Kolb, M. G. Finn, K. B. Sharpless, Angew. Chem. 2001, 113, 2056; Angew. Chem. Int. Ed. 2001, 40, 2004-2021.

[2] J. Lahann (Ed.), Click Chemistry for Biotechnology and Material Science, Wiley, U. K., 2009.

[3] a) V. V. Fokin, P. Wu, in: Aziridines and Epoxides in Organic Synthesis (Ed.: A. K. Yudin), Wiley-VCH, New York, 2006, pp. 443-477; b) Y. Singh, N. Spinelli, E. Defrancq, Curr. Org. Chem. 2008, 12, 263-290; T. S. Zatsepin, D. A. Stetsenko, M. J. Gait, T. S. Oretskaya, Bioconjugate Chem. 2005, 16, 471-489.

[4] C. E. Hoyle, C. N. Bowman, Angew. Chem. 2010, 122, 1584; Angew. Chem. Int. Ed. 2010, 49, 1540-1573.

[5] G. Franc, A. K. Kakkar, Chem. Eur. J. 2009, 15, 5630-5639.

[6] C. W. Tornoe, C. Christensen, M. Meldal, J. Org. Chem. 2002, 67, 3057-3064.

[7] A. Michael, F. Luehn, H. H. Higbee, Am. Chem. J. 1898, 20, 377-395.

[8] R. Huisgen, Angew. Chem. 1963, 75, 604-637.

[9] a) H.-F. Chow, K.-N. Lau, Z. Ke, Y. Liang, C.-M. Lo, Chem. Commun. 2010, 46, 3437-3453; b) Y. Hua, A. H. Flood, Chem. Soc. Rev. 2010, 39, 1262-1271.

[10] R. K. Iha, K. L. Wooley, A. M. Nystrom, D. J. Burke, M. J. Kade, C. J. Hawker, Chem. Rev. 2009, 109, 5620-5686.

[11] a) M. Meldal, Macromol. Rapid Commun. 2008, 29, 1016-1051; b) P. L. Golas, K. Matyjaszewski, Chem. Soc. Rev. 2010, 39, 
1338-1354; c) J.-F. Lutz, Angew. Chem. 2007, 119, 1036; Angew. Chem. Int. Ed. 2007, 46, 1018-1025.

[12] a) S. K. Mamidyala, M. G. Finn, Chem. Soc. Rev. 2010, 39, 1252-1261; b) V. Aragao-Leoneti, V. L. Campo, A. S. Gomes, R. A. Field, I. Carvalho, Tetrahedron 2010, 66, 9475-9492.

[13] J. Cao, X. Huang, J. Comb. Chem. 2008, 10, 526-533.

[14] V. V. Fokin, ACS Chem. Biol. 2007, 2, 775-778.

[15] R. A. Decreau, J. P. Collman, A. Hosseini, Chem. Soc. Rev. 2010, 39, 1291-1301.

[16] E. Lallana, R. Riguera, E. Fernandez-Megia, Angew. Chem. Int. Ed. 2011, 50, 8794-8804.

[17] J. Xu, T. M. Filion, F. Prifti, J. Song, Chem. Asian J. 2011, 6, 2730-2737.

[18] L. M. Gaetke, C. K. Chow, Toxicology 2003, 189, 147-163.

[19] a) J. Gierlich, G. A. Burley, P. M. E. Gramlich, D. M. Hammond, T. Carell, Org. Lett. 2006, 8, 3639-3642; b) J. G. Brewer, Chem. Res. Toxicol. 2010, 23, 319-326.

[20] a) M. E. Martin, S. G. Parameswarappa, M. S. O’Dorisio, F. C. Pigge, M. K. Schultz, Bioorg. Med. Chem. Lett. 2010, 20, 48054807; b) S. Sawoo, P. Dutta, A. Chakraborty, R. Mukhopadhyay, O. Bouloussa, A. Sarkar, Chem. Commun. 2008, 5957-5959.

[21] a) C. Ornelas, J. Ruiz Aranzaes, E. Cloutet, S. Alves, D. Astruc, Angew. Chem. 2007, 119, 890; Angew. Chem. Int. Ed. 2007, 46, 872-877; b) J. Hong, Q. Luo, B. K. Shah, Biomacromolecules 2010, 11, 2960-2965.

[22] J. E. MacDonald, J. A. Kelly, J. G. C. Veinot, Langmuir 2007, 23, 9543-9545.

[23] a) Y. Zou, J. Yin, Bioorg. Med. Chem. Lett. 2008, 18, 5664 5667 b) A. Bernardin, A. Cazet, L. Guyon, P. Delannoy, F. Vinet, D. Bonnaffe, I. Texier, Bioconjugate Chem. 2010, 21, 583-588; c) L. A. Canalle, T. Vong, P. H. M. Adams, F. L. van Delft, J. M. H. Raats, R. G. S. Chirivi, J. C. M. van Hest, Biomacromolecules 2011, 12, 3692-3697.

[24] S. G. Gouin, J. Kovensky, Synlett 2009, 1409-1412.

[25] X. Deng, C. Friedmann, J. Lahann, Angew. Chem. Int. Ed. 2011, 50, 6522-6526.

[26] A. Kiviniemi, P. Virta, H. Lonnberg, Bioconjugate Chem. 2008, 19, 1726-1734.

[27] a) S. Chassaing, M. Kumarraja, A. S. S. Sido, P. Pale, J. Sommer, Org. Lett. 2007, 9, 883-886; b) H. Nulwala, K. Takizawa, A. Odukale, A. Khan, R. J. Thibault, B. R. Taft, B. H. Lipshutz, C. J. Hawker, Macromolecules 2009, 42, 6068-6074; c) B. S. Lee, M. Yi, S. Y. Chu, J. Y. Lee, H. R. Kwon, K. R. Lee, D. Kang, W. S. Kim, H. B. Lim, J. Lee, H.-J. Youn, D. Y. Chi, N. H. Hur, Chem. Commun. 2010, 46, 3935-3937.

[28] T. R. Chan, R. Hilgraf, K. B. Sharpless, V. V. Fokin, Org. Lett. 2004, 6, 2853-2855; D. Soriano del Amo, W. Wan, H. Jiang, C. Besanceney, A. C. Yan, M. Levy, Y. Liu, F. L. Marlow, P. Wu, J. Am. Chem. Soc. 2010, 132, 16893-16899; C. BesanceneyWebler, H. Jiang, T. Zheng, L. Feng, S. del Amo, W. Wang, L. M. Klivansky, F. L. Marlow, Y. Liu, P. Wu, Angew. Chem. Int. Ed. 2011, 50, 8051-8056.

[29] a) E. Paredes, S. R. Das, ChemBioChem 2011, 12, 125-131; b) T. Shiraishi, Y. Kitamura, Y. Ueno, Y. Kitade, Chem. Commun. 2011, 47, 2691-2693.

[30] a) L. Zhang, X. Chen, P. Xue, H. H. Y. Sun, I. D. Williams, K. B. Sharpless, V. V. Fokin, G. Jia, J. Am. Chem. Soc. 2005 , 127, 15998-15999; b) M. M. Majireck, S. M. Weinreb, J. Org. Chem. 2006, 71, 8680-8683; c) S. Oppilliart, G. Mousseau, L. Zhang, G. Jia, P. Thuery, B. Rousseau, J.-C. Cintrat, Tetrahedron 2007, 63, 8094-8098.

[31] a) B. C. Boren, S. Narayan, L. K. Rasmussen, L. Zhang, H. Zhao, Z. Lin, G. Jia, V. V. Fokin, J. Am. Chem. Soc. 2008, 130, 8923-8930; b) L. K. Rasmussen, B. C. Boren, V. V. Fokin, Org. Lett. 2007, 9, 5337-5339.

[32] A. Qin, J. W. Y. Lam, B. Z. Tang, Chem. Soc. Rev. 2010, 39, 2522-2544.

[33] a) D. Imperio, T. Pirali, U. Galli, F. Pagliai, L. Cafici, P. L. Canonico, G. Sorba, A. A. Genazzani, G. C. Tron, Bioorg.
Med. Chem. 2007, 15, 6748-6757; b) F. Wuest, X. Tang, T. Kniess, J. Pietzsch, M. Suresh, Bioorg. Med. Chem. 2009, 17, 1146-1151.

[34] a) U. Pradere, V. Roy, T. R. McBrayer, R. F. Schinazi, L. A. Agrofoglio, Tetrahedron 2008, 64, 9044-9051; b) Tam, U. Arnold, M. B. Soellner, R. T. Raines, J. Am. Chem. Soc. 2007, 129, 12670-12671; c) M. Chemama, M. Fonvielle, M. Arthur, J.-M. Valery, M. Etheve-Quelquejeu, Chem. Eur. J. 2009, 15, 1929-1938; d) D. Crich, F. Yang, Angew. Chem. 2009, 121, 9058; Angew. Chem. Int. Ed. 2009, 48, 8896-8899.

[35] a) N. J. Agard, J. A. Prescher, C. R. Bertozzi, J. Am. Chem. Soc. 2004, 126, 15046-15047; b) E. Lallana, E. Fernandez-Megia, R. Riguera, J. Am. Chem. Soc. 2009, 131, 5748-5750; c) C. Ornelas, J. Broichhagen, M. Weck, J. Am. Chem. Soc. 2010, 132, 3923-3931.

[36] a) E. M. Sletten, C. R. Bertozzi, Org. Lett. 2008, 10, $3097-$ 3099; b) J. A. Codelli, J. M. Baskin, N. J. Agard, C. R. Bertozzi, J. Am. Chem. Soc. 2008, 130, 11486-11493; c) C. A. DeForest, B. D. Polizzotti, K. S. Anseth, Nat. Mater. 2009, 8, 659-664; d) P. V. Chang, J. A. Prescher, E. M. Sletten, J. M. Baskin, I. A. Miller, N. J. Agard, A. Lo, C. R. Bertozzi, Proc. Natl. Acad. Sci. USA 2010, 107, 1821-1826.

[37] a) A. A. Poloukhtine, N. E. Mbua, M. A. Wolfert, G.-J. Boons, V. V. Popik, J. Am. Chem. Soc. 2009, 131, 15769-15776; b) . S. V. Orski, A. A. Poloukhtine, S. Arumugam, L. Mao, V. V. Popik, J. Locklin, J. Am. Chem. Soc. 2010, 132, 11024-11026; c) . K. N. Jayaprakash, C.-G. Peng, D. Butler, J. P. Varghese, M. A. Maier, K. G. Rajeev, M. Manoharan, Org. Lett. 2010, $12,5410-5413$.

[38] a) A. Kuzmin, A. Poloukhtine, M. A. Wolfert, V. V. Popik, Bioconjugate Chem. 2010, 21, 2076-2085; b) F. Starke, M. Walther, H.-J. Pietzsch, ARKIVOC (Gainesville, FL, USA) 2010 , $350-359$.

[39] a) N. E. Mbua, J. Guo, M. A. Wolfert, R. Steet, G.-J. Boons, ChemBioChem 2011, 12, 1912-1921; b) L. S. Campbell-Verduyn, L. Mirfeizi, A. K. Schoonen, R. A. Dierckx, P. H. Elsinga, B. L. Feringa, Angew. Chem. Int. Ed. 2011, 50, 11117-11120.

[40] J. C. Jewett, E. M. Sletten, C. R. Bertozzi, J. Am. Chem. Soc. 2010, 132, 3688-3690.

[41] a) T. Pasinszki, B. Hajgato, B. Havasi, N. P. C. Westwood, Phys. Chem. Chem. Phys. 2009, 11, 5263-5272; b) N. M. Tho, S. Malone, A. F. Hegarty, I. I. Williams, J. Org. Chem. 1991, 56, 3683-3687.

[42] H. Feuer, in: Nitrile Oxides, Nitrones, and Nitronates in Organic Synthesis: Novel Strategies in Synthesis, Wiley, 2008.

[43] a) F. Himo, T. Lovell, R. Hilgraf, V. V. Rostovtsev, L. Noodleman, K. B. Sharpless, V. V. Fokin, J. Am. Chem. Soc. 2005, 127, 210-216; b) B. C. Sanders, F. Friscourt, P. A. Ledin, N. E. Mbua, S. Arumugam, J. Guo, T. J. Boltje, V. V. Popik, G.-J. Boons, J. Am. Chem. Soc. 2011, 133, 949-957.

[44] E. Coutouli-Argyropoulou, P. Lianis, M. Mitakou, A. Giannoulis, J. Nowak, Tetrahedron 2006, 62, 1494-1501.

[45] T. M. V. D. Pinho e Melo, Curr. Org. Chem. 2005, 9, 925-958.

[46] B. L. Deng, T. L. Hartman, R. W. Buckheit, C. Pannecouque, E. De Clercq, M. Cushman, J. Med. Chem. 2006, 49, 53165323.

[47] T. Keicher, S. Lobbecke in Organic Azides: Syntheses and Applications (Eds.: S. Bräse, K. Banert), Wiley, Chichester, 2010, pp. 3-37.

[48] a) T. V. Hansen, P. Wu, V. V. Fokin, J. Org. Chem. 2005, 70, 7761-7764; b) G. Chennakrishnareddy, B. Vasantha, N. Narendra, V. V. Sureshbabu, Int. J. Pept. Res. Therap. 2011, 17, 185191.

[49] S. Kankala, R. Vadde, C. S. Vasam, Org. Biomol. Chem. 2011, 9, 7869-7876

[50] S. Grecian, V. V. Fokin, Angew. Chem. 2008, 120, 8409; Angew. Chem. Int. Ed. 2008, 47, 8285-8287.

[51] T. M. V. D. Pinho e Melo, Eur. J. Org. Chem. 2010, 3363-3376.

[52] A. Basak, K. Chandra, R. Pal, S. C. Ghosh, Synlett 2007, $1585-1588$. 
[53] a) T. K. M. Shing, W. F. Wong, H. M. Cheng, W. S. Kwok, K. H. So, Org. Lett. 2007, 9, 753-756; b) V. V. Vaidya, K. S. Wankhede, M. M. Salunkhe, G. K. Trivedi, Can. J. Chem. 2008, 86, 138-141; c. V. V. Vaidya, K. S. Wankhede, S. J. Nara, M. M. Salunkhe, G. K. Trivedi, Synth. Commun. 2009, 39, 3856-3866.

[54] J. P. Mogensen, S. M. Roberts, A. N. Bowler, C. Thomsen, L. J. S. Knutsen, Bioorg. Med. Chem. Lett. 1998, 8, 1767-1770; S. J. Kim, J. Y. Lee, B. H. Kim, Bioorg. Med. Chem. Lett. 1998, 8, 1313-1316.

[55] a) Y.-S. Lee, B. Hyean Kim, Bioorg. Med. Chem. Lett. 2002, 12, 1395-1397; b) Y.-S. Lee, S. M. Park, H. M. Kim, S.-K. Park, K. Lee, C. W. Lee, B. H. Kim, Bioorg. Med. Chem. Lett. 2009, 19, 4688-4691.

[56] A. M. Jawalekar, E. Reubsaet, F. P. J. T. Rutjes, F. L. van Delft, Chem. Commun. 2011, 47, 3198-3200.

[57] A. Hassner, K. M. L. Rai, Synthesis 1989, 57-59.

[58] a) J. D. Toker, P. Wentworth, Y. F. Hu, K. N. Houk, K. D. Janda, J. Am. Chem. Soc. 2000, 122, 3244-3245; b) M. W. Reed, I. G. Panyutin, D. Hamlin, D. D. Lucas, D. S. Wilbur, Bioconjugate Chem. 1997, 8, 238-243.

[59] V. Padmavathi, K. V. Reddy, A. Padmaja, P. Venugopalan, J. Org. Chem. 2003, 68, 1567-1570.

[60] B. Roy, R. N. De, Monatsh. Chem. 2010, 141, 763-771.

[61] K. M. L. Rai, A. Hassner, Synth. Commun. 1997, 27, 467-472.

[62] a) I. Singh, J. S. Vyle, F. Heaney, Chem. Commun. 2009, 32763278; b) V. Algay, I. Singh, F. Heaney, Org. Biomol. Chem. 2010, 8, 391-397.

[63] S. Liekens, A. Bronckaers, A.-I. Hernandez, E.-M. Priego, E. Casanova, M.-J. Camarasa, M.-J. Perez-Perez, J. Balzarini, Mol. Pharmacol. 2006, 70, 501-509.

[64] a) T. P. Prakash, Chem. Biodiversity 2011, 8, 1616-1641; b) M. Manoharan, Biochim. Biophys. Acta 1999, 1489, 117-130.

[65] I. Singh, F. Heaney, Org. Biomol. Chem. 2010, 8, 451-456.

[66] K. Gutsmiedl, D. Fazio, T. Carell, Chem. Eur. J. 2010, 16, 6877-6883.

[67] R. Lucas, V. Neto, A. Hadj Bouazza, R. Zerrouki, R. Granet, P. Krausz, Y. Champavier, Tetrahedron Lett. 2008, 49, 1004 1007.

[68] J. H. Jeong, H. Mok, Y.-K. Oh, T. G. Park, Bioconjugate Chem. 2009, 20, 5-14.

[69] H. Lonnberg, Bioconjugate Chem. 2009, 20, 1065-1094; Y. Singh, P. Murat, E. Defrancq, Chem. Soc. Rev. 2010, 39, 2054 2070.

[70] a) F. Seela, V. R. Sirivolu, P. Chittepu, Bioconjugate Chem. 2008, 19, 211-224; b) S. S. Pujari, H. Xiong, F. Seela, J. Org. Chem. 2010, 75, 8693-8696.

[71] P. M. E. Gramlich, S. Warncke, J. Gierlich, T. Carell, Angew. Chem. 2008, 120, 3491; Angew. Chem. Int. Ed. 2008, 47, 34423444.

[72] a) A. H. El-Sagheer, T. Brown, Chem. Soc. Rev. 2010, 39, 13881405; b) M. Shelbourne, X. Chen, T. Brown, A. H. El-Sagheer, Chem. Commun. 2011, 47, 6257-6259.

[73] a) G. Pourceau, A. Meyer, Y. Chevolot, E. Souteyrand, J.-J. Vasseur, F. Morvan, Bioconjugate Chem. 2010, 21, 1520-1529; b) G. Pourceau, A. Meyer, J.-J. Vasseur, F. Morvan, J. Org. Chem. 2009, 74, 1218-1222.

[74] a) T. Yamada, C. G. Peng, S. Matsuda, H. Addepalli, K. N. Jayaprakash, M. R. Alam, K. Mills, M. A. Maier, K. Charisse, M. Sekine, M. Manoharan, K. G. Rajeev, J. Org. Chem. 2011, 76, 1198-1211; b) A. V. Ustinov, I. A. Stepanova, V. V. Dubnyakova, T. S. Zatsepin, E. V. Nozhevnikova, V. A. Korshun, Russ. J. Bioorg. Chem. 2010, 36, 401-445.

[75] B. Zhang, W. Wang, D. Qu, Faming Zhuanli Shenqing, 2009, CN 101550175, 2009, 32 pp [CAN 151:523723].

[76] P. Kocalka, N. K. Andersen, F. Jensen, P. Nielsen, ChemBioChem 2007, 8, 2106-2116; M. E. Ostergaard, D. C. Guenther, P. Kumar, B. Baral, L. Deobald, A. J. Paszczynski, P. K.
Sharma, P. J. Hrdlicka, Chem. Commun. 2010, 46, 4929-4931. [77] M. Smietana, R. B. Johnson, Q. M. Wang, E. T. Kool, Chem. Eur. J. 2004, 10, 173-181.

[78] C. Freeman, A. N. Cheallaigh, F. Heaney, Tetrahedron 2011, 67, 7860-7865.

[79] K. Gutsmiedl, C. T. Wirges, V. Ehmke, T. Carell, Org. Lett. 2009, 11, 2405-2408.

[80] T. Plass, S. Milles, C. Koehler, C. Schultz, E. A. Lemke, Angew. Chem. Int. Ed. 2011, 50, 3878-3881.

[81] a) I. S. Marks, J. S. Kang, B. T. Jones, K. J. Landmark, A. J. Cleland, T. A. Taton, Bioconjugate Chem. 2011, 22, 1259-1263; b) P. v. Delft, N. J. Meeuwenoord, S. Hoogendoorn, J. Dinkelaar, H. S. Overkleeft, G. A. v. d. Marel, D. V. Filippov, Org. Lett. 2010, 12, 5486-5489; c) P. van Delft, E. van Schie, N. J. Meeuwenoord, H. S. Overkleeft, G. A. van der Marel, D. V. Filippov, Synthesis 2011, 2724-2732.

[82] L. A. Canalle, M. van der Knaap, M. Overhand, J. C. M. van Hest, Macromol. Rapid Commun. 2011, 32, 203-208.

[83] I. Singh, C. Freeman, F. Heaney, Eur. J. Org. Chem. 2011, 33, 6739-6746.

[84] G. Godeau, C. Staedel, P. Barthelemy, J. Med. Chem. 2008, 51, $4374-4376$.

[85] A. Taherpour, E. Rajaeian, THEOCHEM 2008, 849, 23-24.

[86] C. S. McKay, J. Moran, J. P. Pezacki, Chem. Commun. 2010, 46, 931-933.

[87] X. Ning, R. P. Temming, J. Dommerholt, J. Guo, D. B. Ania, M. F. Debets, M. A. Wolfert, G.-J. Boons, F. L. van Delft, $A n$ gew. Chem. 2010, 122, 3129; Angew. Chem. Int. Ed. 2010, 49, 3065-3068.

[88] H. Ghosh, B. K. Patel, Org. Biomol. Chem. 2010, 8, 384-390.

[89] I. Singh, F. Heaney, Chem. Commun. 2011, 47, 2706-2708.

[90] J. Gierlich, K. Gutsmiedl, P. M. E. Gramlich, A. Schmidt, G. Burley, T. Carell, Chem. Eur. J. 2007, 13, 9486-9494.

[91] a) M. Galibert, P. Dumy, D. Boturyn, Angew. Chem. 2009, 121, 2614; Angew. Chem. Int. Ed. 2009, 48, 2576-2579; b) Z. Jia, C. A. Bell, M. J. Monteiro, Chem. Commun. 2011, 47, 41654167; c) C. A. De Forest, B. D. Polizzotti, K. S. Anseth, Nat. Mater. 2009, 8, 659-664; d) T. Kang, R. J. Amir, A. Khan, K. Ohshimizu, J. N. Hunt, K. Sivanandan, M. I. Montañez, M. Malkoch, M. Ueda, C. J. Hawker, Chem. Commun. 2010, 46, 1556-1558.

[92] K. Kempe, R. Hoogenboom, M. Jaeger, U. S. Schubert, Macromolecules 2011, 44, 6424-6432.

[93] V. Aucagne, D. A. Leigh, Org. Lett. 2006, 8, 4505-4507.

[94] a) K. P. Kaliappan, P. Kalanidhi, S. Mahapatra, Synlett 2009, 2162-2166; b) X. Peng, H. Li, M. Seidman, Eur. J. Org. Chem. 2010, $4194-4197$.

[95] a) P. A. Ledin, F. Friscourt, J. Guo, G.-J. Boons, Chem. Eur. J. 2011, 17, 839-846; b) P. Kele, G. Mezo, D. Achatz, O. S. Wolfdeis, Angew. Chem. 2009, 121, 350; Angew. Chem. Int. Ed. 2009, 48, 344-347.

[96] S. Hilf, A. F. M. Kilbinger, Nature Chem. 2009, 1, 537-546.

[97] R. M. J. Liskamp, D. T. S. Rijkers, R. J. Pieters, A. J. Brouwer, J. A. F. Joosten EP 1733742 2006, CAN 146:87720.

[98] a) T. Matsumura, F. Ishiwari, Y. Koyama, T. Takata, Org. Lett. 2010, 12, 3828-3831; b) Y.-G. Lee, Y. Koyama, M. Yonekawa, T. Takata, Macromolecules 2010, 43, 4070-4080.

[99] a) Y. Koyama, M. Yonekawa, T. Takata, Chem. Lett. 2008, 37, 918-919; b) Y.-G. Lee, Y. Koyama, M. Yonekawa, T. Takata, Macromolecules 2009, 42, 7709-7717; c) Y.-G. Lee, M. Yonekawa, Y. Koyama, T. Takata, Chem. Lett. 2010, 39, 420-421.

[100] I. Ito, T. Takada Y. Koyama, JP 2010037289, 2010 CAN 152:262378.

[101] a) I. Singh, Z. Zarafshani, F. Heaney, J.-F. Lutz, Macromolecules 2009, 42, 5441-5443; b) I. Singh, Z. Zarafshani, F. Heaney, J.-F. Lutz, Polym. Chem. 2011, 2, 372-375.

Received: December 19, 2011 Published Online: March 13, 2012 